\title{
Spatial and temporal distribution of vertical ground movements at Mt. Vesuvius in the period 1973-2009
}

\author{
Folco Pingue $^{1, \star}$, Milena Bottiglieri ${ }^{2}$, Cataldo Godano ${ }^{2}$, Francesco Obrizzo ${ }^{1}$, \\ Umberto Tammaro $^{1}$, Teodoro Esposito ${ }^{3}$, Claudio Serio ${ }^{1}$ \\ ${ }^{1}$ Istituto Nazionale di Geofisica e Vulcanologia, Sezione di Napoli, Osservatorio Vesuviano, Naples, Italy \\ ${ }^{2}$ Seconda Università di Napoli, Dipartimento di Matematica e Fisica, Caserta, Italy \\ ${ }^{3}$ Università di Napoli "Federico II", Dipartimento di Scienze della Terra, dell'Ambiente e delle Risorse, Naples, Italy
}

\author{
Article history \\ Received August 21, 2012; accepted February 1, 2013. \\ Subject classification: \\ Measurements and monitoring, Ground deformation, Precision leveling, Mount Vesuvius, Volcanism.
}

\begin{abstract}
Since the early'70s vertical ground movements at Mount Vesuvius area have been investigated and monitored by the Osservatorio Vesuviano (Istituto Nazionale di Geofisica Vulcanologia - Osservatorio Vesuviano since 2001). This monitoring began with the installation of a high-precision leveling line in the region at medium-high elevations on the volcano. The deformation pattern and expected strain field assessment methods in the volcanic structure induced by inner sources has demanded in subsequent years the expansion of the leveling network up to cover the whole volcanic area, enclosing part of leveling lines of other institutions. As a result of this expansion, the Mt. Vesuvius Area Leveling Network (VALN) has today reached a length of about $270 \mathrm{~km}$ and consists of 359 benchmarks. It is configured in 21 circuits and is connected, westward, to the Campi Flegrei leveling network and, northward, to the Campania Plain leveling network. The data collected have been carefully re-analyzed for random and systematic errors and for error propagation along the leveling lines to identify the areas affected by significant ground movements. For each survey, the data were rigorously adjusted and vertical ground movements were evaluated by differentiating the heights calculated by the various measurements conducted by the Osservatorio Vesuviano from 1973 to 2009.
\end{abstract}

\section{Introduction}

The volcanic complex of Somma-Vesuvius is a stratovolcano located in the southern sector of Campania Plain (Figure 1) together with other Neapolitan volcanoes (Campi Flegrei caldera, Ischia island, and eruptive centers of Naples city).

Neapolitan volcanic area is bordered on the north by Campania Plain, on the East by Sarno Plain, and on the South by Gulf of Naples. Volcanic activity of SommaVesuvius is related to the geodynamic processes that generated the extension of the western edge of the southern Apennines, the opening of the Tyrrhenian Sea, the crustal thinning and formation of the Campania Plain graben [Finetti and Del Ben 1986, Luongo et al. 1991, Patacca and Scandone 2007, Vezzani et al. 2010]. The graben is bordered by tectonic lines (e.g. Mount Massico, Mount Maggiore, and Sorrento peninsula) with a NW-SE and NE-SW trend.

The volcanic system consists of the older Mt. Somma and younger Mt. Vesuvius, that is located within the caldera of Mt. Somma formed about 18,000 year BP [Landi et al. 1999]. Currently, the caldera rim (maximum altitude $1131 \mathrm{~m}$ a.s.1.) is well preserved in the northern sector. Mt. Vesuvius is a nearly symmetrical cone, which reaches $1281 \mathrm{~m}$ a.s.1. and was formed through the accumulation of lava flows, ash and scoria emitted mainly from the central vent.

The volcanic activity in the area dates back to about 400,000 years ago [Brocchini et al. 2001, Cubellis et al. 2007], although Mt. Vesuvius volcano was formed about 25,000 years ago, about 8000 years before the collapse of the Somma caldera [Delibrias et al. 1979]. Geological and volcanological data [Carta et al. 1981, Santacroce 1983, Santacroce and Sbrana 2003] show the occurrence of several subplinian and plinian eruptions. This intense period of activity was followed by a quiescent period lasting several centuries until the devastating Plinian eruption in 79 A.D. [Luongo et al. 2003, Marturano 2008, Marturano et al. 2011].

After some centuries, during which we have very few data, a subplinian eruption occurred in 472 A.D., followed by a persistent activity lasting about 700 years [Mastrolorenzo et al. 2002, Rolandi et al. 2004]. A long period of low activity began in the 12th century and lasted until 1631, when the volcano resumed activity 
with a subplinian eruption which was followed by a period of small and medium-size eruptions until 1944. This last eruption marked the beginning of a period characterized by only fumarolic activity [Chiodini et al. 2001, Frondini et al. 2004] and low level seismicity [Bianco et al. 1998, De Natale et al. 1998, 2004], generally characterized by earthquake swarms [Bianco et al. 1999].

The ground deformation is a geophysical parameter that contributes to the unrest assessment of eruptive activity in medium-term [Dvorak and Dzurisin 1997, Dzurisin 2000, 2003]. The measurement of the vertical displacement field in an active volcanic area gives indications of the crustal stress distribution changes related to the magma dynamics. The observations available for several decades (more than one hundred years) on active volcanoes show that a significant percentage of preeruptive stages are accompanied by seismicity, geochemical variations and ground deformation. The precision leveling is a widely used technique for the measurement of vertical ground displacements [Pelton and Smith 1982].

This methodology, recently supplemented by other methods like GPS and INSAR, has been used for a long time in active volcanic areas to model sources and the complex mechanisms of magma ascent [Mogi 1958, Corrado et al. 1976, Obrizzo et al. 2001, Beauducel et al. 2004, Obrizzo et al. 2004, Battaglia et al. 2006]. This technique allows to achieve a millimeter accuracy in

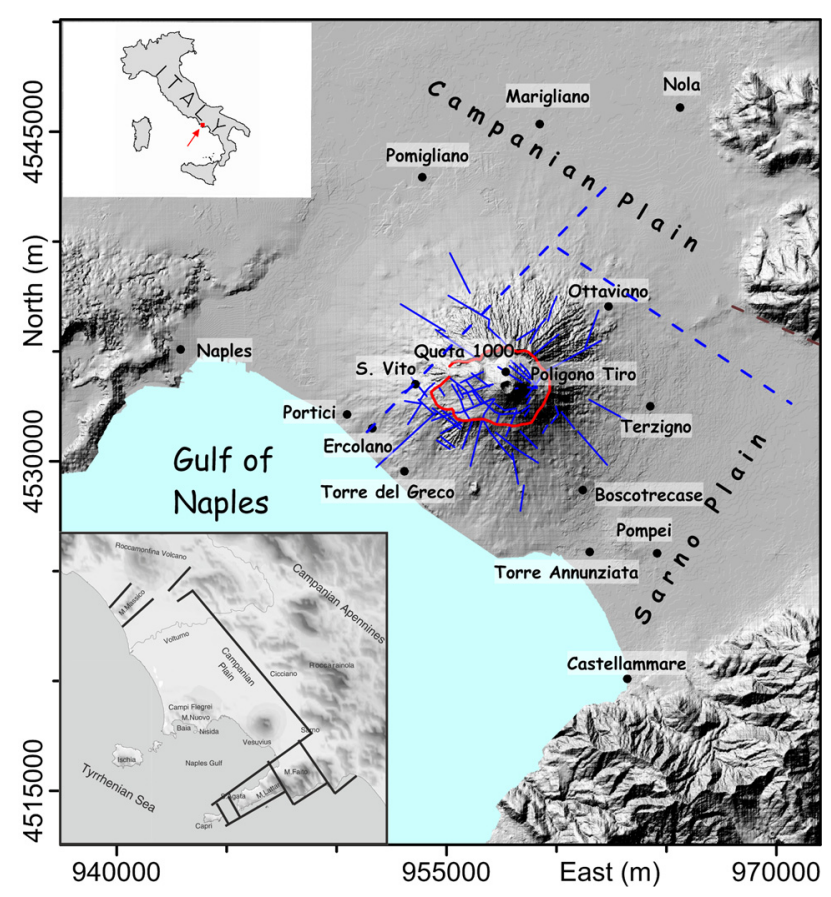

Figure 1. Sketch map of Mt. Vesuvius area. The main volcano-tectonic lineaments insistent on Somma-Vesuvius volcanic complex are shown (blue lines). The red solid line represents the Somma caldera rim (redrawn after Ventura and Vilardo [1999]). The insert at the bottom shows the Campania plain graben with the main tectonic lines. Some peculiar place names are also shown. the height estimation of the measured benchmark.

The volcanic history, geologic structures and tectonic dynamics of the investigated area, and the knowledge of the magma ascent processes, are among the most important elements for the design and the geometrical configuration of the geodetic (leveling, GPS, Tilt, Gravimetry, tide gauge), seismic and geochemical monitoring systems.

The first experiments using this methodology on Mt. Vesuvius was conducted in December 1861. Luigi Palmieri (then director of the Osservatorio Vesuviano) carried out measurements of height variations using a "telescope-level" along the fractures that were opened in the town of Torre del Greco (on the southern flank of Mt. Vesuvius) during the eruption that caused damage and destruction in this city [Palmieri et al. 1862].

The first precision leveling on Mt. Vesuvius was carried out by Loperfido [1914]. He installed and measured a leveling line about $11 \mathrm{~km}$ long, which started from the bottom of the volcano (Ercolano) and ascended the southern flank of Mt. Vesuvius reaching the crater, where a close loop was installed along the crater rim. The benchmarks of this small network were lost (presumably destroyed by the 1944 eruption), except for two points located near the Osservatorio Vesuviano historical building (altitude 600 meters). They were measured in 1959, showing a subsidence of about $-20 \mathrm{~cm}$ [Giannoni 1962].

In 1959 a larger leveling network was setup on the southern part of Mt. Vesuvius [Giannoni 1962] reaching the Quota 1000 area.

Beginning from 1973 the Osservatorio Vesuviano installed a new "Vesuvius Area Leveling Network" (VALN) that expanded in the following years reaching in 2009 a length of about $270 \mathrm{~km}$ with 359 benchmarks forming 21 circuits (Figure 2).

In this paper we analyze the data collected from 1973 to 2009 to identify the areas affected by significant vertical ground movements.

\section{Vesuvius Area Leveling Network (VALN): design, in- stallation and evolution}

In the early '70s the Osservatorio Vesuviano began a study aimed at the design and installation of a precision leveling network to monitor the vertical ground movements of Mt. Vesuvius. Since it is an active volcano for a long time in a quiescent phase, there are not enough and sufficiently reliable information on the pattern field of ground deformation that can characterize the various phases of activities (pre-eruptive, eruptive and post-eruptive). The lack of such data led to the decision to expand, albeit gradually, the leveling network up to cover the whole volcanic complex. 


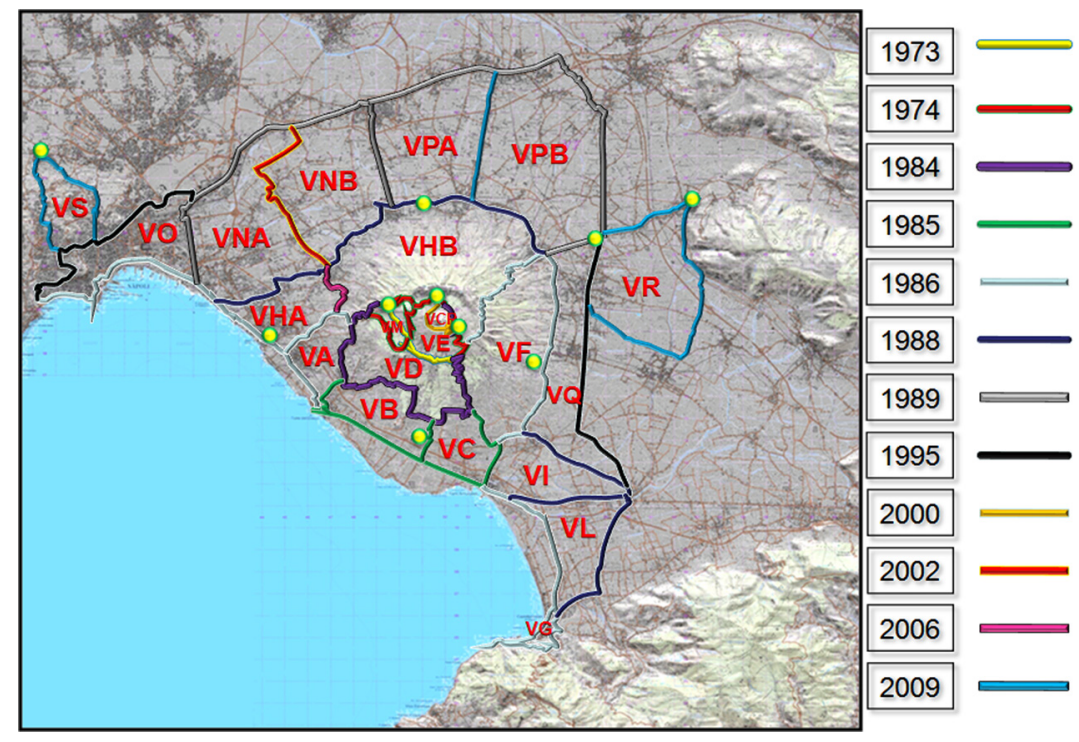

Figure 2. Temporal evolution of the Vesuvian Area Leveling Network (VALN). The colors indicate the installation date of the corresponding leveling sections. The names of the 21 circuits leveling are reported. The circles represent the GPS vertices connected to VALN.

Between 1973 and 1974, 25 benchmarks were setup in the upper middle part of the volcano (between 500 and 1000 meters of altitude) configured in four leveling lines [Bonasia et al. 1974]. The network was about $20 \mathrm{~km}$ long and enclosed the Vesuvius Gran Cono with the exception of the northeast side (Figure 2). This rather small leveling network remained unchanged until 1984 and several surveys were conducted until September 1982, always following the criteria required for the first order leveling [Commissione Geodetica Italiana 1975]. The collected data were analyzed using as a reference the IGM benchmark placed close to the Osservatorio Vesuviano building. This benchmark was considered the most suitable, being located in a relatively stable area of the volcano on the oldest structure of Mt. Somma. The analysis of this dataset referred only to the upper part of the volcano and revealed a modest subsidence trend in areas characterized by incoherent soil and very steep slope [Bonasia and Pingue 1981, Bonasia et al. 1985]. These authors highlighted the need to expand the leveling network toward lower altitudes and far from the volcano, in order to study the vertical movement of other areas of the volcano and to find a reference benchmark with greater stability.

Therefore, a progressive expansion of the leveling network toward the southwestern area was carried out. In 1986 the VALN was connected to the Campi Flegrei leveling network and to the limestones of the Sorrento Peninsula allowing the use of the same reference benchmark used in Campi Flegrei leveling network and located in Naples. At that time the whole network was about $120 \mathrm{~km}$ long with 154 benchmarks.

In the following years, in addition to set up several benchmarks on the southern rim of Mt. Vesuvius crater, the enlargement of the network in the northern sector was also carried out. The coverage of the entire SommaVesuvius volcanic complex was completed, connecting the network at north with the IGM leveling lines operating in the Sannio and Irpinia seismogenic areas. (Figure 2). We remark that in 2009 we have connected the leveling network to the GPS 3D vertices of the permanent GPS network of the Neapolitan volcanic area (Figure 2) [Bottiglieri et al. 2007, 2010, Tammaro et al. 2013]. The Vesuvius leveling network consists today of 359 benchmarks, distributed over an area of about $250 \mathrm{~km}^{2}$. It covers the total emerged volcanic area, from Naples to Castellammare, and extends inland to the towns of Pomigliano d'Arco and Mari-gliano. With a length of about $270 \mathrm{~km}$, the network is structured in 21 circuits (Figure 2) all connected to each other in order to allow a cross-check and a rigorous adjustment of measurements. This procedure, after fixing of the reference benchmark altitude, estimates the most probable elevation (in the minimum square sense) of all other benchmarks.

The present density and spatial distribution of the leveling benchmarks ensures the detection of the entire Somma-Vesuvius vertical movements, and of differential movements of specific areas, even small, on the surface. The former are possibly related to processes such as pressure increase at depth, while the second are likely related to magma rising to the surface. The last mechanism should induce a superficial asymmetry in the stress field due to preferential paths through structural weaknesses of the crust.

In Table 1 we show the evolution of the VALN network along the years through the number of installed benchmarks, length of the network and the number of circuits.

Many papers have dealt with the analysis of data from this network. In particular, Pingue and Esposito 


\begin{tabular}{|c|c|c|c|c|}
\hline Survey & \# bm & $\begin{array}{c}\mathrm{L} \\
(\mathbf{k m})\end{array}$ & \# Loops & Note \\
\hline $3 / 1973$ & 9 & 5 & 0 & \\
\hline $10 / 1973$ & 9 & 5 & 0 & \\
\hline 1974 & 25 & 17 & 0 & \\
\hline 1976 & 26 & 17 & 0 & \\
\hline 1977 & 26 & 17 & 0 & \\
\hline 1978 & 26 & 17 & 0 & \\
\hline 1979 & 26 & 17 & 0 & \\
\hline 1980 & 26 & 17 & 0 & \\
\hline 1981 & 26 & 17 & 0 & \\
\hline 1982 & 26 & 17 & 0 & \\
\hline 1984 & 54 & 39 & 0 & \\
\hline 1985 & 21 & 18 & 0 & \\
\hline 1986 & 154 & 120 & 11 & \\
\hline 1988 & 213 & 158 & 11 & \\
\hline $03 / 1989$ & 36 & 36 & 0 & Partial survey \\
\hline $11 / 1989$ & 236 & 197 & 13 & \\
\hline 1990 & 247 & 196 & 13 & \\
\hline 1992 & 248 & 196 & 13 & \\
\hline 1994 & 248 & 196 & 13 & \\
\hline 1995 & 287 & 224 & 15 & \\
\hline 1996 & 284 & 223 & 15 & \\
\hline 1997 & 280 & 222 & 15 & \\
\hline 1999 & 280 & 222 & 15 & \\
\hline 2000 & 291 & 226 & 16 & \\
\hline 2002 & 298 & 236 & 17 & \\
\hline 2003 & 98 & 66 & 1 & Partial survey \\
\hline 2004 & 298 & 233 & 17 & \\
\hline 2006 & 220 & 160 & 13 & Partial survey \\
\hline 2009 & 359 & 270 & 21 & \\
\hline
\end{tabular}

Table 1. Principal characteristics of leveling surveys.

[1988] presented a detailed and critical report of the leveling measures, available until 1986. They show that, using the Ercolano benchmark as reference, in the 27 years between 1959 and 1986, the coastline shows a very slight subsidence trend, whereas benchmarks located on the volcano flanks show a modest uplift with a rate of a few $\mathrm{mm} /$ year. Several authors report leveling data analysis as they become available [Bonasia et al. 1974, Bonasia and Pingue 1981, Bonasia et al. 1985, Pingue and Esposito 1994, Pingue et al. 2000]. Berrino et al. [1993] carried out an analysis of the whole geophysical dataset (seismic, gravimetric, tide gauge, tilt- meter and leveling data), available for the Vesuvius area at that time. All these analysis have evidenced no significant vertical movements related to the internal dynamics of the volcano. Slight subsidence are observed at a few benchmarks, likely due to local effects.

\section{Data acquisition and analysis of height differences}

From March 1973 to November 2009, 29 surveys were carried out (Table 1). The first 12 were conducted before 1986 and are limited to the central part of Mt. Vesuvius (from 100 meters to 1000 meters a.s.1.), without reaching the crater area. The successive surveys, instead, cover larger areas and use the benchmark LNA/001 (within Naples) as a reference. It must be noted that 3 surveys were carried out only over part of the network. The first one (March 1989) measured only few benchmarks located north of the volcano. Other two surveys (2003 and 2006) cover only part of the southern flank of Mt. Vesuvius.

In the following we briefly describe the various surveys carried out from 1973 to 2009 and report the main features of the height differences measured between successive benchmarks and the closure errors of the closed leveling circuits.

All measurements were made using one or more automatic optical levels (e.g. Wild NA2) with parallelplate micrometer and invar rods, calibrated before each survey. The double-run field procedure was used, which helps to detect any blunders, identify and reduce both systematic and random errors. The maximum allowed discrepancy between forward and backward measurements of consecutive benchmark was set to $\pm 2.5 \times\left(\mathrm{L}_{\mathrm{km}}\right)^{1 / 2} \mathrm{~mm}$, where $\mathrm{L}_{\mathrm{km}}$ is the length in kilometers of the leveling section. In the case of close circuits the closure error (i.e. the height difference accumulated along the loop) must not exceed the value of $\pm 2.0 \times\left(\mathrm{C}_{\mathrm{km}}\right)^{1 / 2} \mathrm{~mm}$, where $\mathrm{C}_{\mathrm{km}}$ represents the loop length in kilometers [Commissione Geodetica Italiana 1975].

In cases of open leveling lines, the correctness of data has been provided only verifying that the absolute value of the discrepancy of each leveling section was not greater than the allowed tolerance. In the case of closed circuits, it has also verified that the error of closure of each loop was compatible with the tolerance acceptable according to its length. To estimate the accuracy of leveling measurements we analyze the observed height differences between consecutive benchmarks. Table 2 shows the main characteristic data related to the discrepancies calculated for each survey.

In Figure 3 (1st column) the discrepancy versus section length are shown for each survey. We see that almost all discrepancies of each measurement campaign 


\begin{tabular}{|c|c|c|c|c|c|c|c|c|}
\hline Year & $\begin{array}{l}\text { Number } \\
\text { of discrep. }\end{array}$ & $\begin{array}{l}\text { Min. } \\
(\mathrm{mm})\end{array}$ & $\begin{array}{l}\text { Max. } \\
(\mathrm{mm})\end{array}$ & $\begin{array}{l}\text { Mean } \\
(\mathrm{mm})\end{array}$ & $\begin{array}{l}\text { Stand. dev. } \\
\quad(\mathbf{m m})\end{array}$ & $\mathbf{R}^{2}$ value & $\begin{array}{l}\text { Skewness } \\
\quad(\mathrm{mm})\end{array}$ & $\begin{array}{c}\text { Kurtosis } \\
\text { (mm) }\end{array}$ \\
\hline $3 / 1973$ & 8 & -1.34 & 0.73 & -0.09 & 0.68 & 0.0841 & 0.5484 & -0.6272 \\
\hline $10 / 1973$ & 8 & -1.14 & 1.49 & 0.00 & 0.77 & 0.3245 & 0.4895 & 0.4143 \\
\hline 1974 & 24 & -2.34 & 1.79 & 0.00 & 1.24 & 0.3950 & -0.3212 & -1.3321 \\
\hline 1976 & 25 & -1.41 & 2.48 & 0.27 & 1.00 & 0.0330 & 0.3191 & -0.4087 \\
\hline 1977 & 25 & -2.27 & 2.30 & 0.17 & 1.11 & 0.0000 & -0.2416 & -0.1860 \\
\hline 1978 & 25 & -2.46 & 2.10 & 0.24 & 1.03 & 0.0103 & -0.6347 & 0.3595 \\
\hline 1979 & 25 & -2.87 & 2.97 & 0.01 & 1.65 & 0.0002 & 0.0312 & -1.2161 \\
\hline 1980 & 25 & -1.96 & 2.72 & 0.10 & 1.28 & 0.1172 & 0.3618 & -0.8415 \\
\hline 1981 & 26 & -2.39 & 2.99 & -0.27 & 1.38 & 0.0263 & 0.6739 & 0.3895 \\
\hline 1982 & 26 & -2.93 & 3.75 & 0.60 & 2.07 & 0.0238 & 0.4911 & -0.0422 \\
\hline 1984 & 57 & -2.84 & 2.74 & -0.25 & 1.41 & 0.0229 & 0.0655 & -0.6630 \\
\hline 1985 & 20 & -3.42 & 3.48 & 0.41 & 1.71 & 0.1122 & -0.3582 & -0.1032 \\
\hline 1986 & 162 & -3.59 & 3.89 & 0.21 & 1.42 & 0.0127 & -0.0349 & 0.0581 \\
\hline 1988 & 224 & -3.07 & 3.48 & 0.39 & 1.27 & 0.0006 & -0.2288 & -0.3986 \\
\hline $03 / 1989$ & 35 & -2.42 & 2.50 & 0.02 & 1.34 & 0.0134 & 0.0546 & -0.8917 \\
\hline $11 / 1989$ & 248 & -2.77 & 2.58 & -0.01 & 1.27 & 0.0018 & 0.0101 & -1.0387 \\
\hline 1990 & 259 & -2.47 & 2.74 & 0.63 & 1.10 & 0.0041 & -0.8385 & 0.0624 \\
\hline 1992 & 260 & -2.25 & 2.51 & 0.04 & 1.10 & 0.0038 & 0.0545 & -0.8509 \\
\hline 1994 & 260 & -2.00 & 2.30 & 0.34 & 1.07 & 0.0050 & -0.3099 & -0.9589 \\
\hline 1995 & 301 & -2.19 & 2.33 & -0.02 & 1.07 & 0.0003 & 0.1025 & -1.0248 \\
\hline 1996 & 298 & -2.43 & 2.60 & 0.19 & 1.16 & 0.0005 & -0.1650 & -0.9133 \\
\hline 1997 & 294 & -2.33 & 1.77 & 0.26 & 0.84 & 0.0037 & -0.4460 & 0.4771 \\
\hline 1999 & 294 & -2.06 & 2.04 & 0.07 & 0.93 & 0.0360 & -0.1290 & -0.8007 \\
\hline 2000 & 306 & -2.04 & 2.08 & 0.20 & 0.96 & 0.0382 & -0.2862 & -0.9105 \\
\hline 2002 & 315 & -1.86 & 2.00 & 0.33 & 0.84 & 0.0168 & -0.3882 & -0.7344 \\
\hline 2003 & 101 & -1.34 & 2.01 & 0.76 & 0.63 & 0.2041 & -0.3771 & 0.2169 \\
\hline 2004 & 314 & -2.28 & 2.19 & 0.51 & 0.97 & 0.0007 & -0.6293 & -0.1660 \\
\hline 2006 & 232 & -1.69 & 1.76 & 0.46 & 0.65 & 0.0104 & -0.7238 & 0.4944 \\
\hline 2009 & 379 & -1.70 & 1.70 & 0.48 & 0.60 & 0.0001 & -0.4496 & -0.5116 \\
\hline
\end{tabular}

Table 2. Statistics of leveling discrepancies.

are lower than the allowed tolerance of $\pm 2.5 \times\left(\mathrm{L}_{\mathrm{km}}\right)^{1 / 2}$ $\mathrm{mm}$, and a significant percentage is even smaller than $\pm 1.0 \times\left(\mathrm{L}_{\mathrm{km}}\right)^{1 / 2}$. Furthermore, there is no significant linear correlation with the length; in fact, the coefficient of determination $R^{2}$ is in the range $0 \div 0.3950$ with an average of only 0.0518 (Table 2).

Figure 3 (2nd and 3rd columns) also shows relative frequency distribution of the discrepancy between backward and forward readings. The average value lies in the range $-0.27 \div 0.76$ and the standard deviation in the worst case is about $2 \mathrm{~mm}$. It can be inferred that the distributions are generally uni-modal with the central value close to zero and very small standard deviations. Only some cases with few observations show a bimodal distribution, imputable to lack of data.

To test the observations we evaluate, for normal distribution, the skewness $\gamma_{1}=\mu_{3} / \sigma^{3}$ (where $\mu_{3}$ is the empirical third central moment and $\sigma$ is the standard deviation) and the kurtosis $\gamma_{2}=\mu_{4} / \sigma^{4}-3$ (where $\mu_{4}$ is the empirical fourth central moment and $\sigma$ is the standard deviation). Table 2 lists the values of skewness and kurtosis of the discrepancy distribution of all leveling surveys in the period 1973-2009. The skewness covers a range from -0.8385 to 0.6739 with an average $=-0.1159$, 

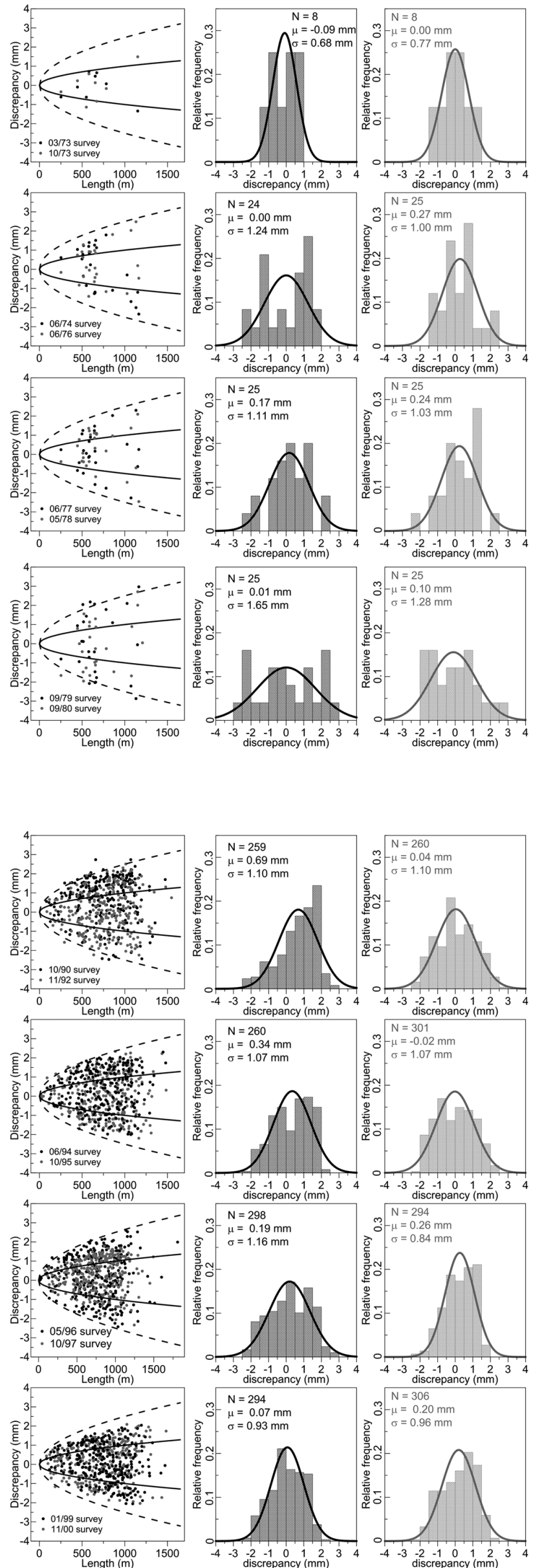
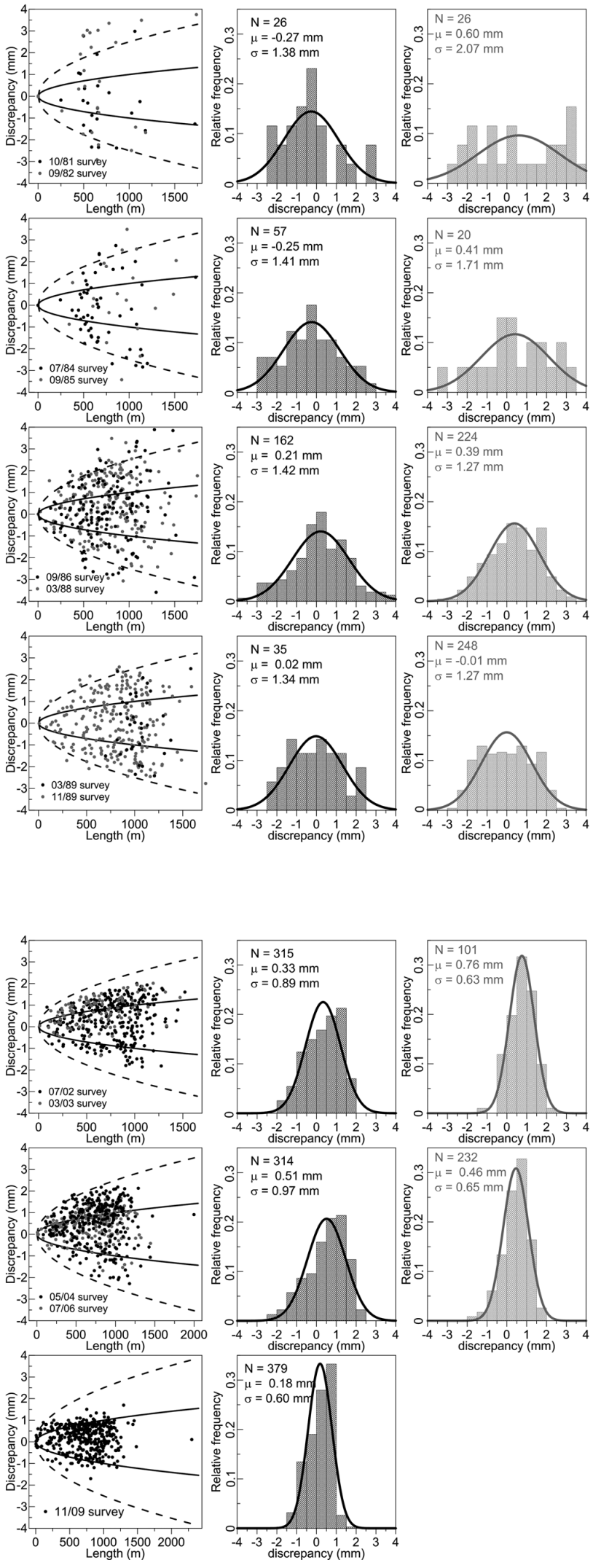

Figure 3. Discrepancy distributions for the 29 surveys analyzed in this paper. Each graph of the first column shows the discrepancy versus the length of the leveling sections for two consecutive surveys, except the last one which is referred to only one survey. The other columns show the histogram of the discrepancy. The Gaussian curve which best approximate the distribution is also shown. 
while the average kurtosis is equal to -0.4189 (with a range between -1.3321 and 0.4944 ). There are no significant correlation between the values of kurtosis and skewness with the number of available observations (Figure 4). Only a slightly higher dispersion of these parameters is observed when a smaller number of observations is available.

The 29 surveys carried out from 1973 to 2009 involved nearly 700 leveling sections between two successive benchmarks, 485 of which were measured at least twice in the considered temporal period.

To assess the significance of variations versus time of these relative height at each pair of successive benchmarks we used the method of variance analysis. The hypothesis that height differences of the $\mathrm{i}^{\text {th }}$ time series are all equal (null hypothesis) is verified if $F_{i} \leq F_{c}=$ $F_{m-1, N-m, \alpha}$, for the $\mathrm{i}^{\text {th }}$ time series, where $\mathrm{m}$ is the number of samples, $N$ is the total number of observations and $\alpha$ is the chosen confidence level.

This analysis was applied to the available $485 \mathrm{lev}$ eling sections that are in the dataset with at least two measures. By choosing a confidence level of $5 \%$, we verified that the value $F$ is higher than the corresponding critical value $F_{c}$ in 125 cases ( $25.8 \%$ of total cases), and therefore the null hypothesis is rejected.

It is very interesting to observe the spatial distribution of leveling sections for which the hypothesis of common average of the correspondent height difference is rejected by the analysis of variance. Figure 5 shows in red the midpoint positions of all the leveling sections whose temporal trend is not stationary.

It is clear that some of these segments are sparsely distributed in the N-NW area of Mt. Vesuvius, generally interested by a non-significant dynamics. On the contrary, a group of segments exhibiting a non-stationary signal is located in the SE area of the volcano characterized by flat and alluvial terrain (the Sarno river plain). This densely populated zone is affected by ground movements related to the aquifer dynamics [Cascini et al. 2006, Fabbrocino et al. 2007].

The majority of non-stationary leveling segments are concentrated on the volcano, from $500 \mathrm{~m}$ of altitude up to the crater rim. This zone is characterized by soft and incoherent pyroclastic materials and was already identified as an unstable area [Bonasia et al. 1985]. Others non-stationary leveling segments are located on the flanks of the volcano characterized by steep slopes.

\section{Adjustment of leveling data and elevation time series}

From 1973 to 1985 the leveling network for monitoring the activity of Mt. Vesuvius consisted of a few benchmarks, located at the top of the volcano from about 500 to $1000 \mathrm{~m}$ a.s.l. These benchmarks were

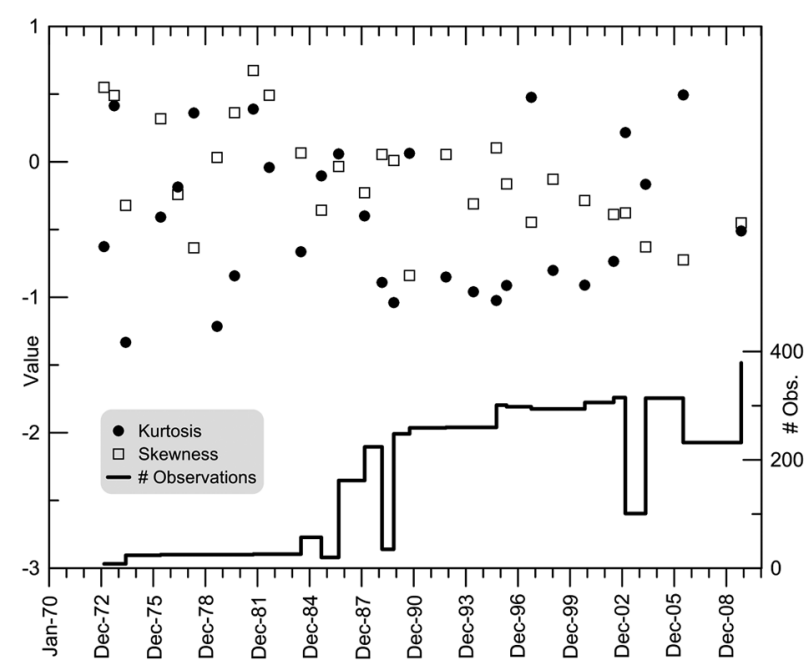

Figure 4. Kurtosis and Skewness of the discrepancy distributions of each leveling survey. The solid line shows the trend in the number of measured height differences.

placed along open leveling lines and only since 1986 some circuits were closed, allowing a first cross-check data. This poor configuration resulted in the impossibility of finding a reference benchmark far enough from the monitored area. Therefore, in such cases no rigorous data adjustment was made and quality control was carried out only by checking that the discrepancies of each leveling segment and the loop closures were smaller than the allowed tolerances.

At the beginning of 1986 survey the VALN network was further expanded and was also connected to

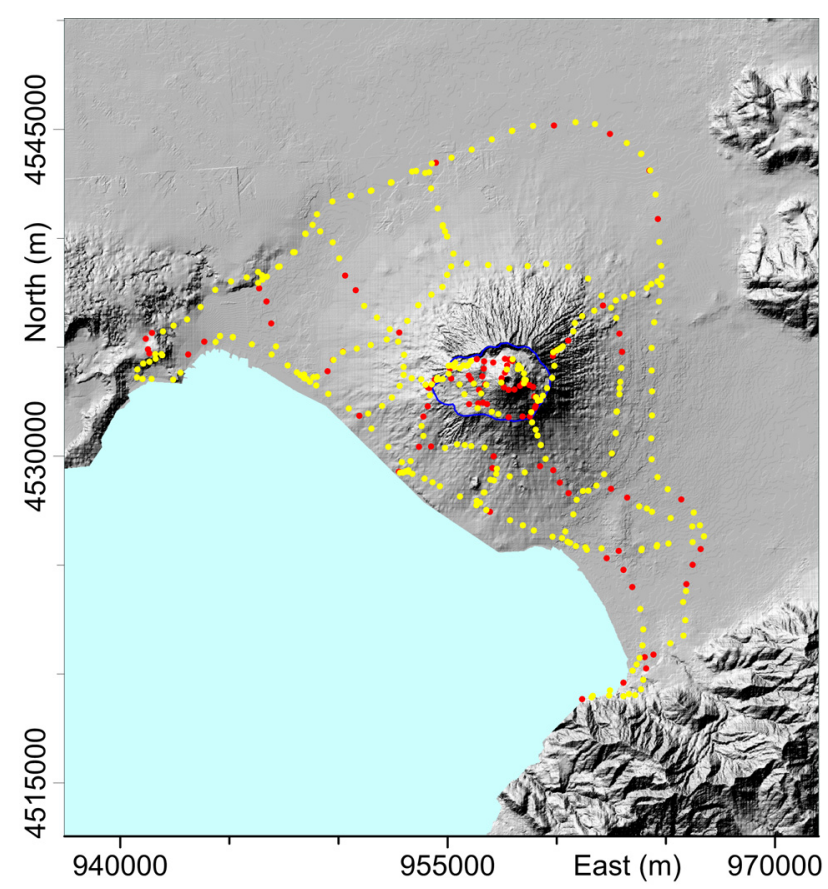

Figure 5. Location map of the leveling section midpoints measured at least twice. The stationary (yellow) and the non-stationary (red) sections are also shown. Stationarity analysis has been performed using variance analysis. The blue solid line represents the rim of the Somma caldera. 


\begin{tabular}{|c|c|c|c|c|c|}
\hline Survey & $\begin{array}{l}\text { Number } \\
\text { of sections }\end{array}$ & $\begin{array}{c}\text { Number } \\
\text { of unknowns }\end{array}$ & $\begin{array}{l}\text { Length } \\
(\mathrm{km})\end{array}$ & $\begin{array}{c}\text { Maximum residual } \\
(\mathrm{mm})\end{array}$ & $\underset{(\mathrm{mm})}{\sigma_{0}}$ \\
\hline 1986 & 162 & 153 & 120 & 1.14 & 1.80 \\
\hline 1988 & 224 & 212 & 158 & 1.40 & 1.72 \\
\hline $11 / 1989$ & 248 & 235 & 197 & 1.24 & 1.45 \\
\hline 1990 & 259 & 246 & 196 & 0.95 & 1.58 \\
\hline 1992 & 260 & 247 & 196 & 1.11 & 1.11 \\
\hline 1994 & 260 & 247 & 196 & 0.78 & 1.07 \\
\hline 1995 & 301 & 286 & 224 & 1.09 & 1.43 \\
\hline 1996 & 298 & 283 & 223 & 0.75 & 1.03 \\
\hline 1997 & 294 & 279 & 222 & 0.67 & 1.22 \\
\hline 1999 & 294 & 279 & 222 & 0.65 & 1.02 \\
\hline 2000 & 306 & 290 & 226 & 0.81 & 1.10 \\
\hline 2002 & 315 & 297 & 236 & 0.78 & 1.14 \\
\hline 2003 & 101 & 97 & 66 & 0.69 & 0.69 \\
\hline 2004 & 314 & 297 & 233 & 0.83 & 1.02 \\
\hline 2006 & 232 & 219 & 160 & 0.45 & 0.72 \\
\hline 2009 & 379 & 358 & 270 & 1.14 & 1.14 \\
\hline
\end{tabular}

Table 3. Principals parameters of adjustment survey data.

the adjacent Campi Flegrei leveling network. The shared benchmark, located in Naples (bm LNA/001), was used as altitude reference. Therefore, the data of each survey from 1986 to 2009 were processed by a rigorous adjustment process, obtaining the most probable height of the unfixed benchmarks with respect to the height of the reference $\mathrm{H}_{\mathrm{LNA} / 001}=2.754 \mathrm{~m}$. The data of the survey carried out in March 1989 have not been adjusted, because only 36 benchmarks, not connected with the reference benchmark, were used. Table 3 shows for each survey some characteristic numbers concerning the adjustment process. These provide useful information on the quality of collected data and their mutual consistency.

Sometimes it has happened that some benchmarks have been lost by various causes. In general they have been replaced, during the subsequent survey, with a new benchmark placed very close to the lost one. Therefore, the altitude time series of these benchmarks show an offset caused by the benchmark replacement. Of course, there are no contemporary measurement executed on both benchmarks. The time series discontinuities were eliminated by evaluating the rates of the series before and after the interruption. In detail, if $q_{1}$ and $q_{2}$ are the altitude calculated at time $t_{1}$ and $t_{2}\left(t_{1}<t_{2}\right)$ and $q_{3}$ and $q_{4}$ are the corresponding height at the times $t_{3}$ and $t_{4}\left(t_{2}<\right.$ $<t_{3}<t_{4}$ ), the offset has been eliminated by adding to all altitudes $q_{i}$ at time $t_{i} \leq t_{2}$ the constant quantity:
$C=\left(q_{3}-q_{2}\right)-$

$$
-\frac{\left(q_{2}-q_{1}\right) \times\left(t_{4}-t_{3}\right)+\left(q_{4}-q_{3}\right) \times\left(t_{2}-t_{1}\right)}{2 \times\left(t_{2}-t_{1}\right) \times\left(t_{4}-t_{3}\right)} \times\left(t_{3}-t_{2}\right) .
$$

Using this simple procedure 52 time series have been reconstructed, allowing a better sampling of the vertical displacement pattern for each pair of measurements. In conclusion, we have 312 altitude time series of many benchmarks (with a common reference) spanning from 1986 to 2009. Each of them is constituted by a number of points in the range 2-16. These data can be considered sufficient, in terms of quantity and geometrical distribution, to estimate the vertical displacement pattern at the Somma-Vesuvius area from 1986 to 2009.

Data show that a clear characteristic of the movements is a strong predominance of subsidence movements. Figure 6a shows the vertical displacement range in each survey with respect to the previous one. The same quantity is plotted as percentage in Figure $6 \mathrm{~b}$. The cumulative range and distribution are shown in Figure $6 \mathrm{c}$ and $6 \mathrm{~d}$. It is evident that the Somma Vesuvius volcanic area is in a subsidence phase, especially since 1999.

The map of vertical displacements provides useful information on the distribution on the most active areas. As an example, Figure 7 shows the map of vertical displacements for the whole period 1986-2009 using the common points to the 1986 and the 2009 surveys. 


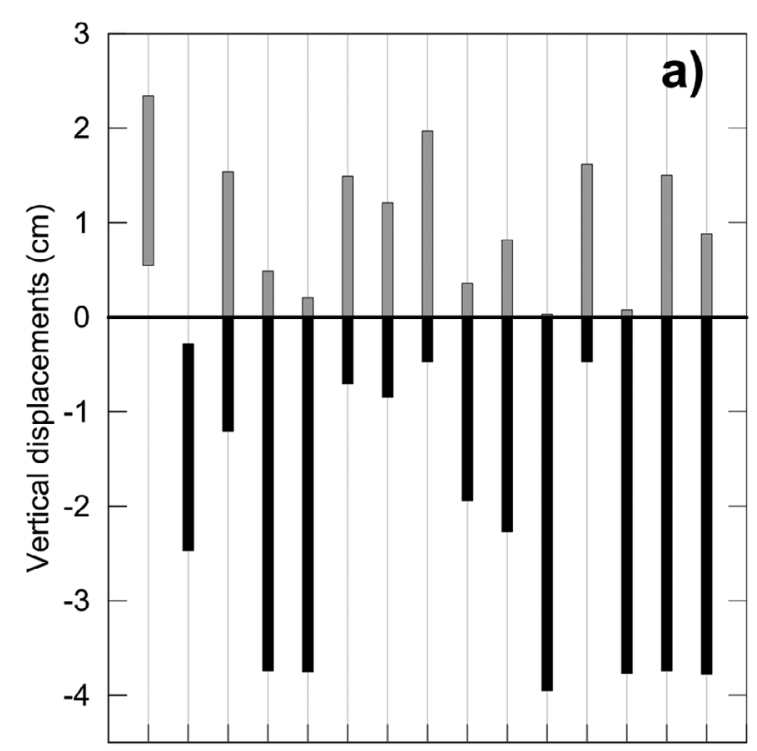

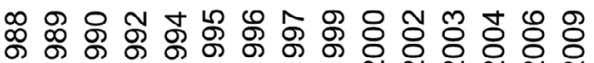
\% \% $\frac{0}{\div} \%$ 品。 \&

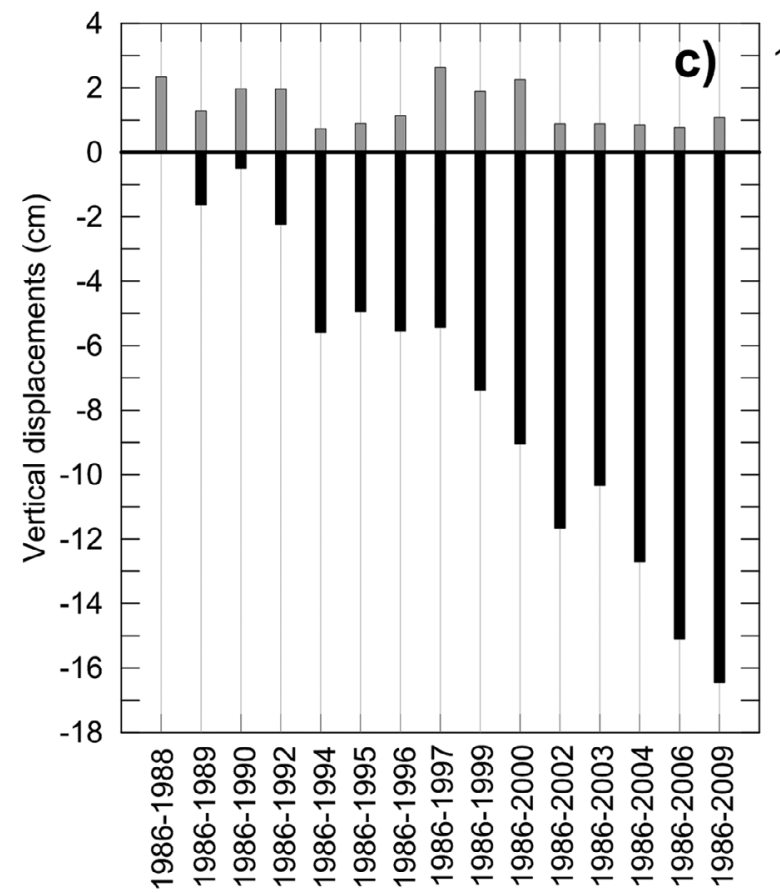

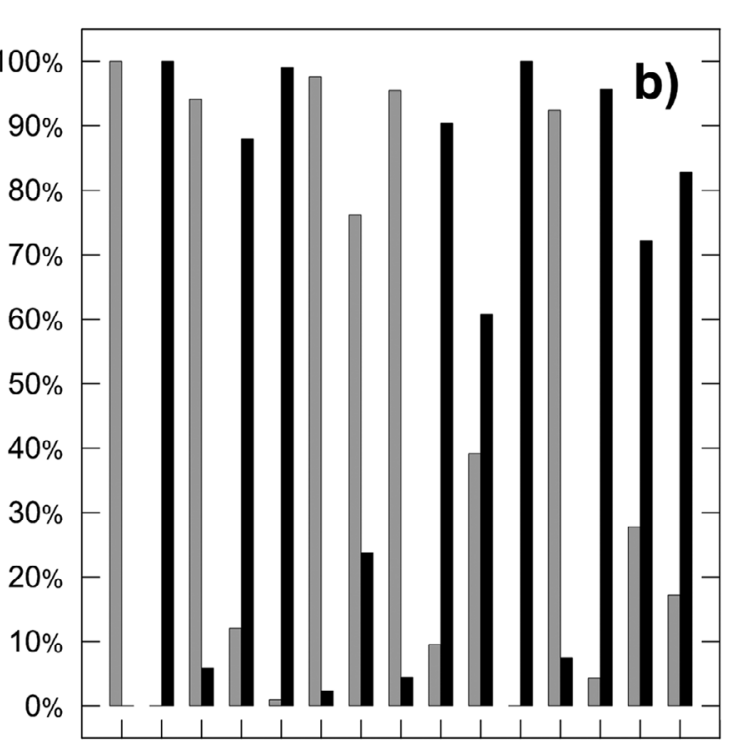

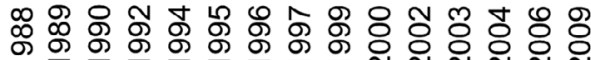

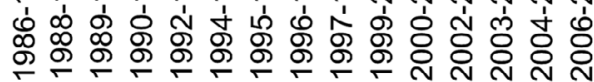

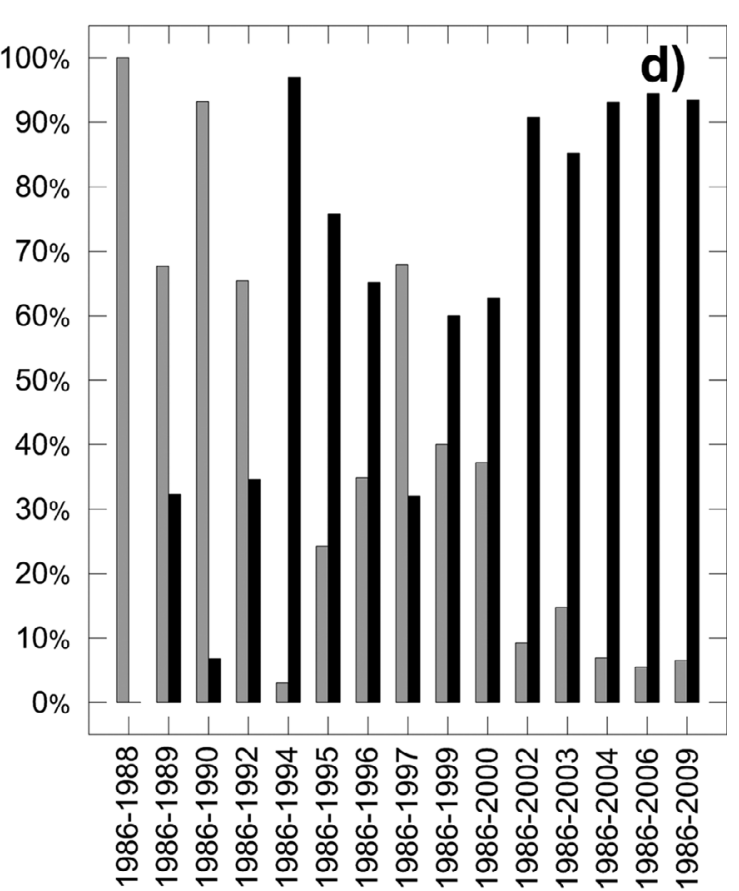

Figure 6. (a) Bar graph which represents the range of the benchmark vertical displacement calculated between each survey and the previous one. (b) Percentage of benchmarks showing positive (gray) and negative (black) elevation changes. The panels c) and d) correspond respectively to a) and b), but for elevation variations cumulated from 1986 onwards.

The common benchmarks exclude the northern and the extreme eastern parts of the present network and, more important, the most of Gran Cono. Figure 8 shows, as an example, the height variation calculated at four characteristic profiles in the period 1986-2009, running a) from Naples to Castellammare along the coast, b) from Castellammare to Poligono di Tiro (1000 $\mathrm{m}$ a.s.l. climbing on the southeastern flank of the volcano), c) from Naples to Ercolano-Quota 1000 (1000 m a.s.l. climbing along the southwestern flank). The fourth profile (d) is a circuit that covers the southern part of the volcano from about $100 \mathrm{~m}$ a.s.l. to about 650 $\mathrm{m}$ a.s.l. The first profile exhibits a slow subsidence from Naples to Castellamare (approximately $-4 \mathrm{~cm}$ in about $40 \mathrm{~km}$ ). Second and third profiles show an almost flat behavior up to the benchmarks located on the Somma caldera border, about $600-800 \mathrm{~m}$ a.s.l. Here the vertical displacement gradient increases significantly in both profiles. More precisely the subsidence reaches the value of $-16.50 \mathrm{~cm}$ at $\mathrm{bm} \mathrm{LVE/013} \mathrm{along} \mathrm{the} \mathrm{profile}$ b), whereas it assumes the value $-15.25 \mathrm{~cm}$ along the profile c). Finally, the profile d) in Figure 8 shows a sub- 


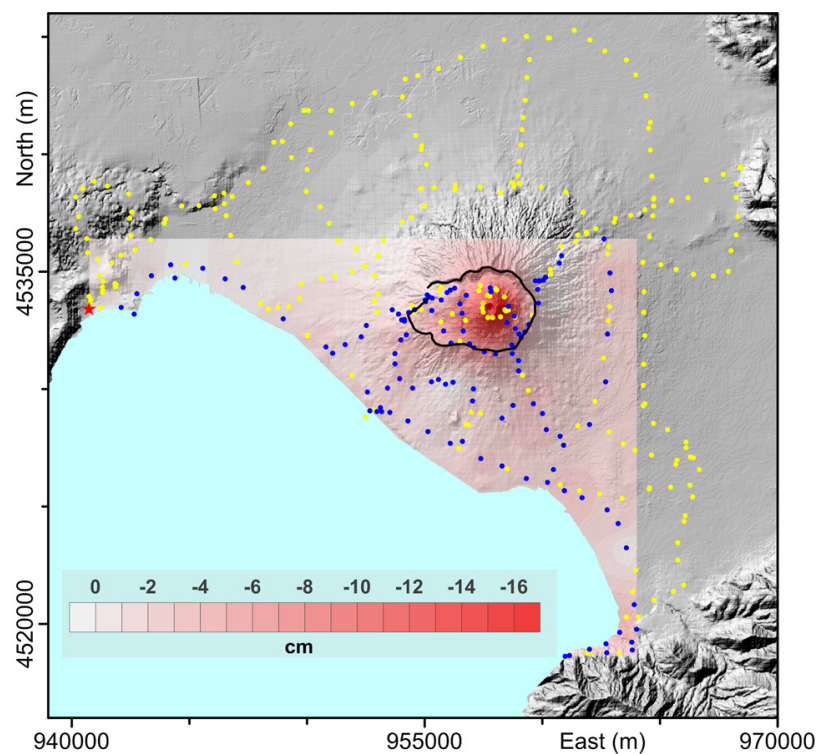

Figure 7. Map of the vertical displacement field for the period 19862009. The benchmarks common to the two surveys are shown in blue. The rim (solid line) of the Somma caldera is also showed. The red star indicates the reference benchmark location.

sidence greater than $-10 \mathrm{~cm}$ at benchmarks placed on higher altitude part of circuit, about $600 \mathrm{~m}$ a.s.l. close to the Somma caldera rim, and a much less significant sub-
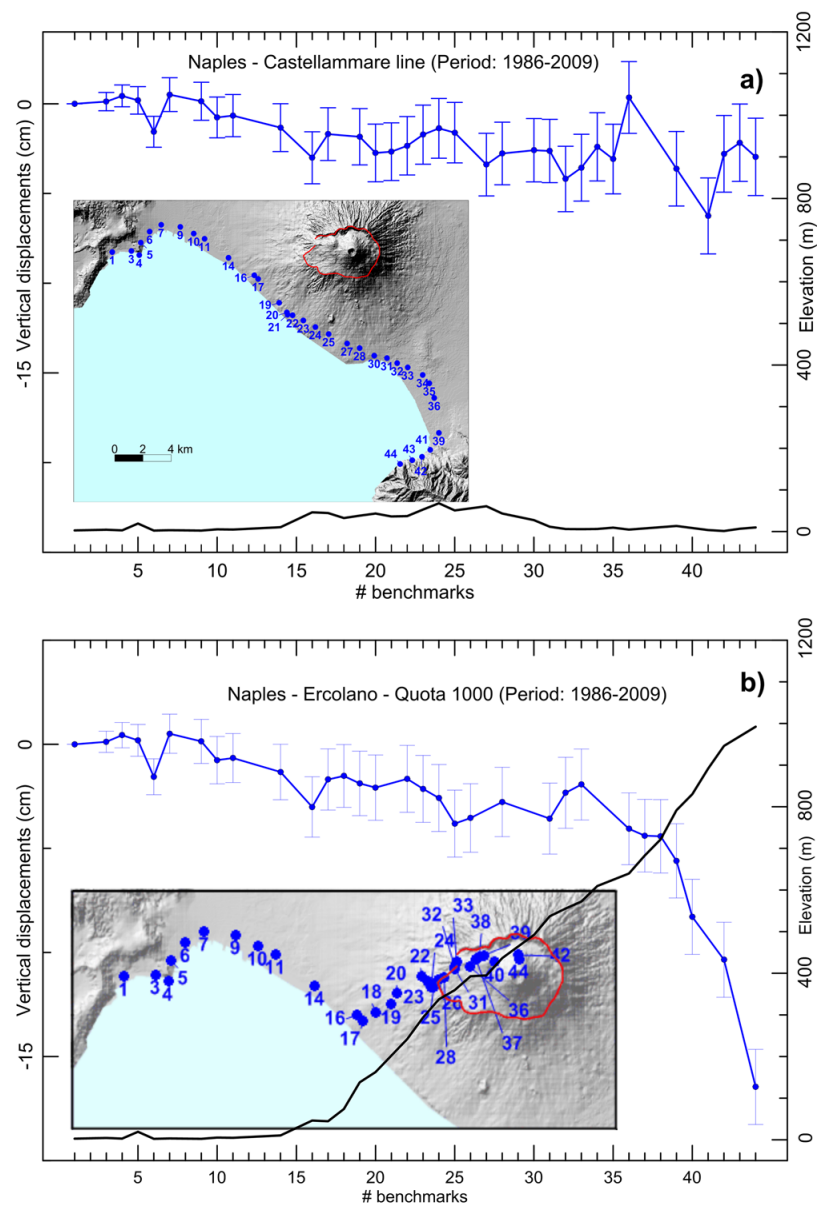

sidence (on average in the range $-5 \div-3 \mathrm{~cm}$ ) on the edge of the profile at lower elevation. Surprisingly we observe that the gradient increase along the three profiles occurs at about $700 \mathrm{~m}$ a.s.l., coinciding with the inner limit of the Somma caldera. This result indicates that the whole Somma caldera, including the Gran Cono area, is affected by a subsidence phenomenon greater than that affecting the area at altitude lower than about $700 \mathrm{~m}$, showing that vertical movements are also affected by the topography [Meo et al. 2008]. Interestingly the Sarno river Plain, east of the volcano, is also affected by a subsidence ranging between -2 and $-5 \mathrm{~cm}$ along both the profiles a) and c) of Figure 8. On the contrary we do not observe any significant vertical displacement in the northwest area of Mt. Vesuvius, approaching the reference benchmark.

Finally, during the time period 1986-2009, there is no direct information concerning the movements of the areas at the crater rim, and the north and east flanks of the volcano, because here there were no benchmarks in 1986. The crater rim benchmarks were placed in 2000 , thus, to obtain information on movements of these areas, we computed the map of vertical movements for the period 2000-2009 (Figure 9) and the height variations
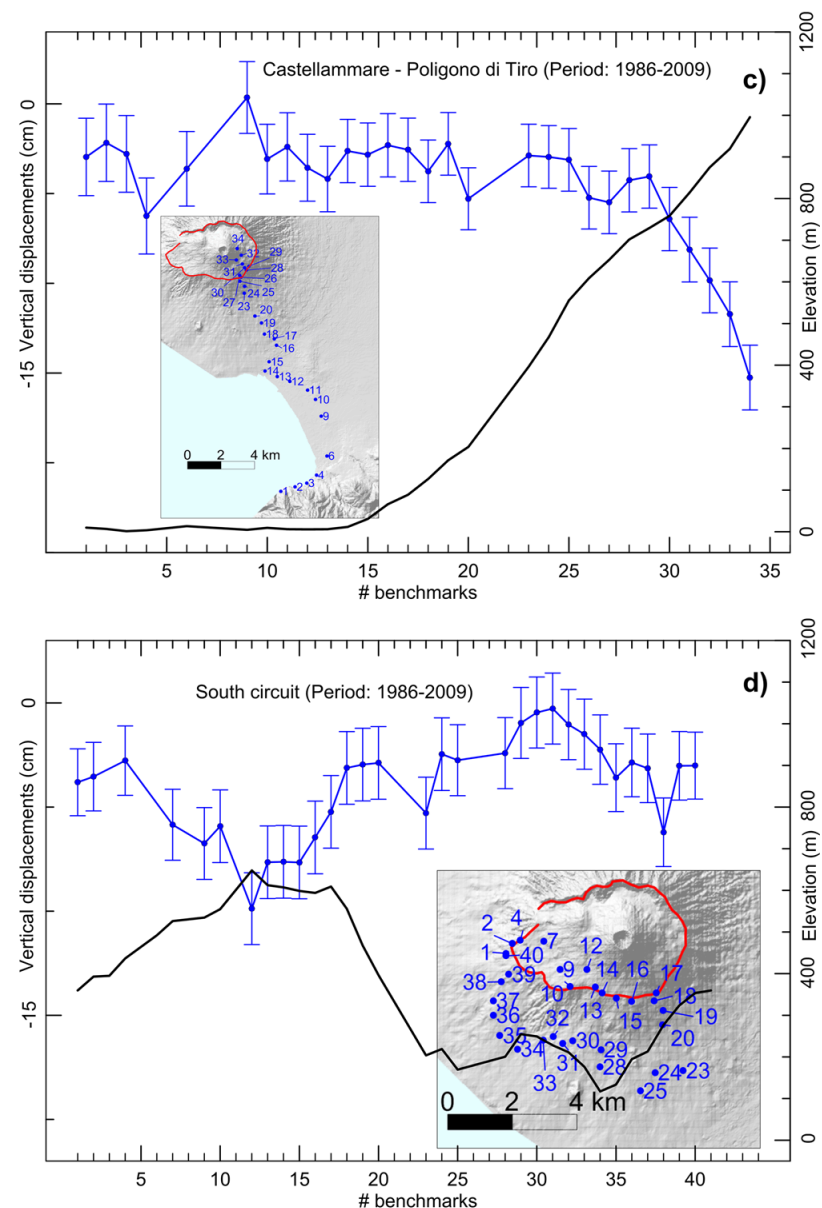

Figure 8. Elevation variations measured for the period 1986-2009 on the benchmarks of 4 particular leveling profiles. The inset shows the locations of the involved points with the rim of the Somma caldera (red line). 
on benchmarks located on crater loop (Figure 10). It is clear that the subsidence increases going up to the crater rim. Indeed, the benchmark of maximum subsidence in this period (bm LVE/ 190) is placed just on the southern rim of the crater and exhibits a subsidence of about $-14 \mathrm{~cm}$, almost double than the subsidence highlighted at bm LVE/013 (located at base of the Gran Cono) which was the benchmark with the greatest subsidence in the previous configuration of the VALN.

We now analyze the temporal behavior of the vertical ground movements considering a group of benchmarks with different height a.s.l. and located on areas with different geological and structural characteristics (Figure 11). The altitude variations versus time for this group of benchmarks is shown in Figure 12. The almost constant temporal decrease of the displacements for the whole Vesuvius area has been confirmed, albeit with different subsidence rates. The altitude is well enough linearly correlated with time, as shown by the linear fit (Figure 12). It should be highlighted that the rate of subsidence increases with altitude. Indeed, it is of the order of $1 \mathrm{~mm} /$ year for the coastline (for example at bm $083 / 064$ ), reaches values of about $10 \mathrm{~mm} /$ year as you climb up to the base of the Gran Cono (for instance at bm LVE/013 and bm LVE/026) and exceeds $15 \mathrm{~mm} / \mathrm{yr}$ at crater rim (for example at bm GEVE/ 24 and bm LVE/190). Notice that benchmarks located on the Sarno river Plain, although placed at low altitudes $(<100 \mathrm{~m}$ a.s.1.), exhibit subsiding rates 2-3 times higher than that found at the benchmarks along the coast (northwest direction).

\section{Temporal analysis of the altitudes}

To approach the question if the altitude is stationary, we have investigated the 312 altitude time series described in the previous section. Among these we selected those with at least 6 points to ensure a sufficiently robust statistical analysis. This reduces the number of series to 290. At this point of analysis we prefer a more strict criterion for selecting stationary signals with respect to the one used for the height difference analysis. The choice is a consequence of the error reduction in using the adjusted measures. Therefore we decided to apply the Student $t$-test to all possible couples of measures for each benchmark separately, taking into account only records with a number of measures $n \geq 6$. The $t$-test has been performed at a confidence level of $5 \%$. If just one couple of data points did not get through the test, the series has been considered not stationary. The choice took in consideration any possible existence of variation. We found 47 non-stationary data series, referring to the benchmarks whose location is shown in Figure 13. These data series have been normalized in

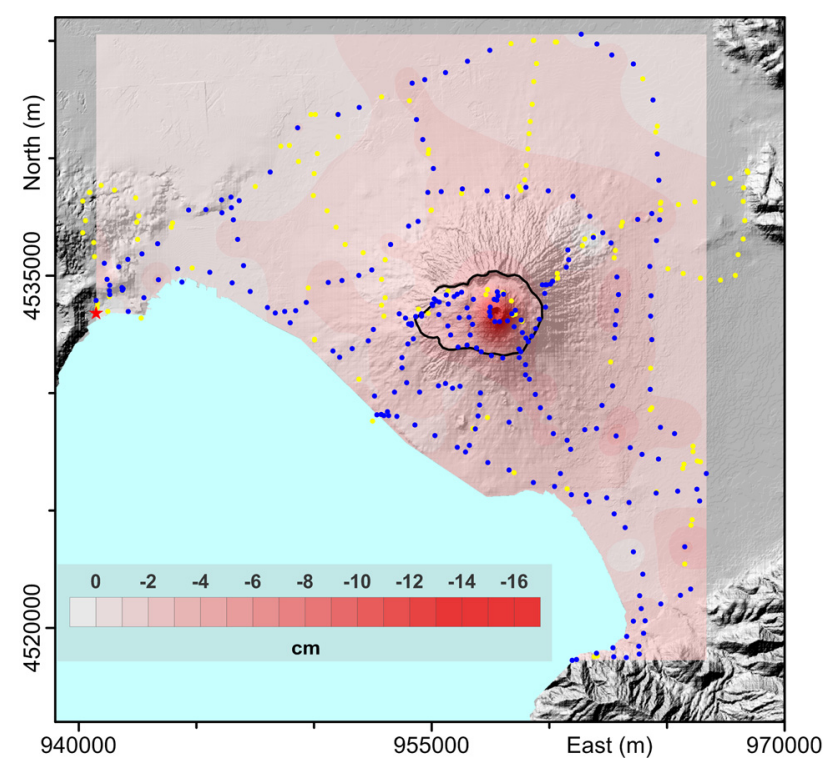

Figure 9. Map of the vertical displacement field for the period 20002009. The benchmarks common to the two surveys are shown in blue. The rim (solid line) of the Somma caldera is also shown. The star indicates the reference benchmark location.

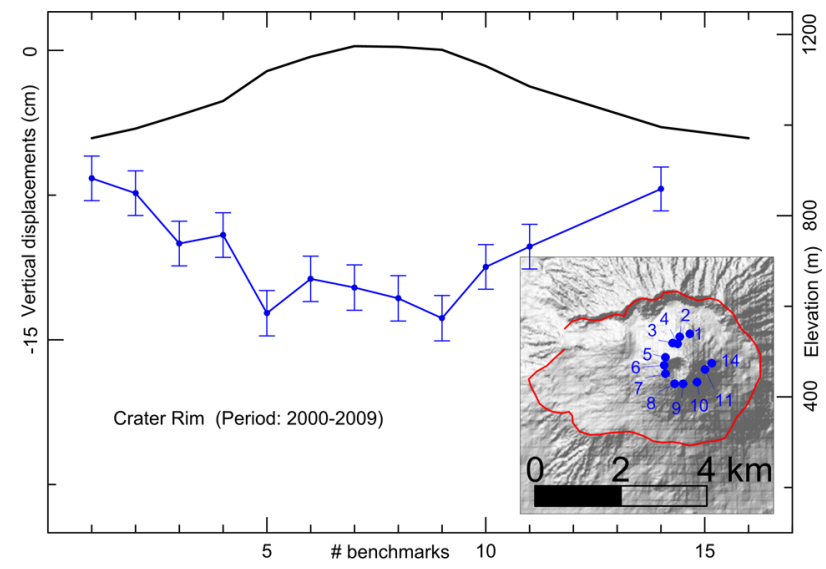

Figure 10. Elevation variations measured for the period 2000-2009 on the benchmarks of a profile that includes the edge of the Vesuvius crater. The inset shows the locations of the involved points with the rim of the Somma caldera (red line).

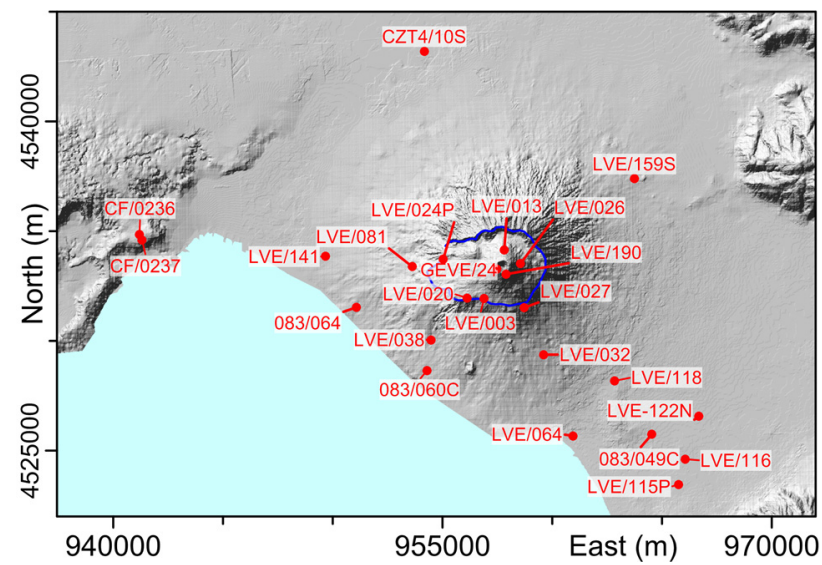

Figure 11. Map showing the location of some selected benchmarks whose vertical displacements time series are shown in Figure 12. The blue line represents the rim of the Somma caldera. 
PINGUE ET AL.
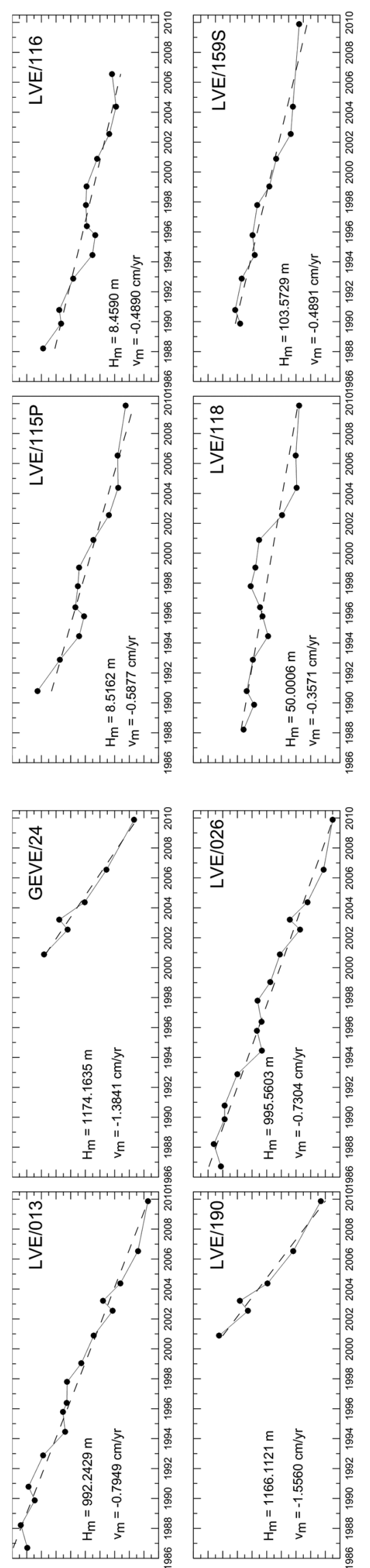
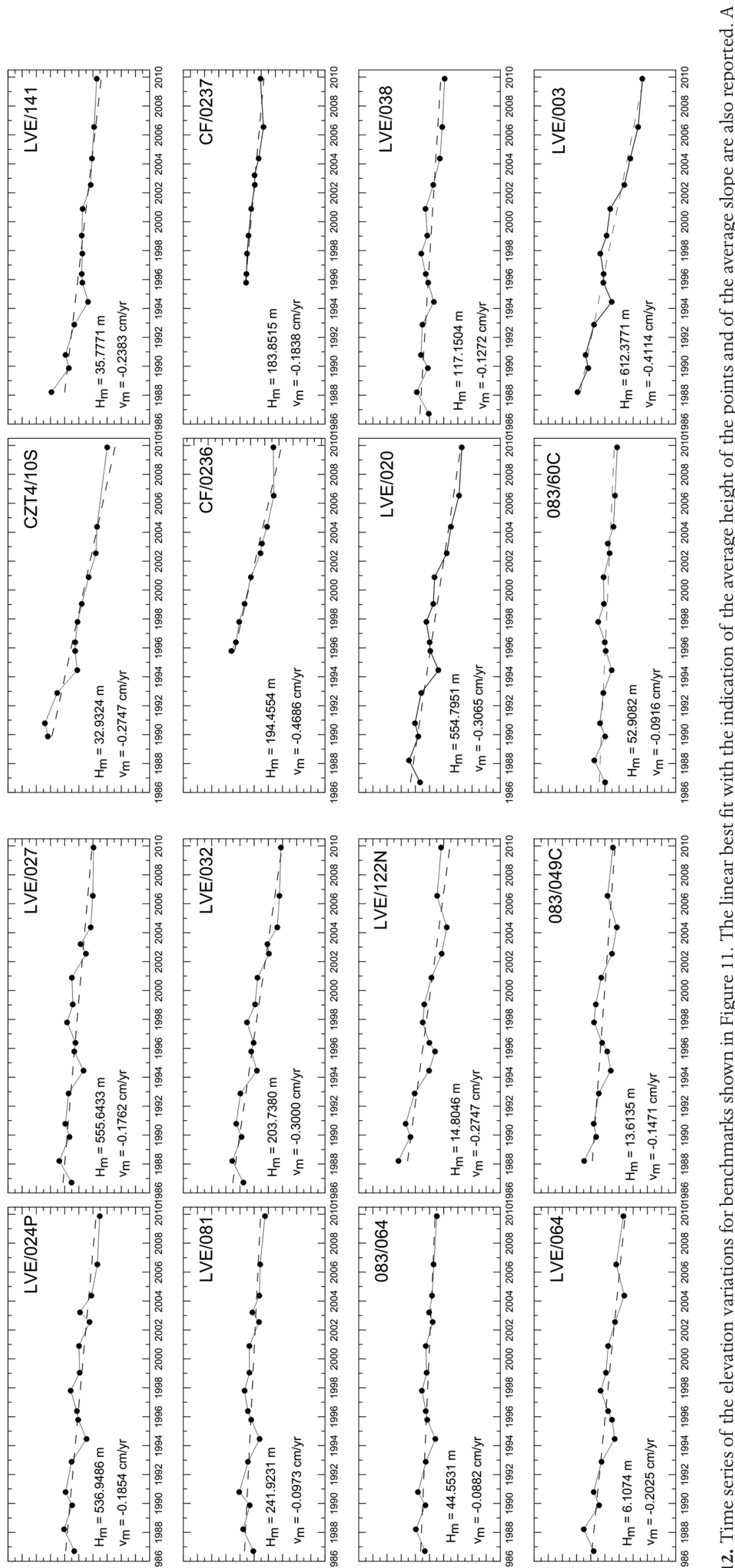

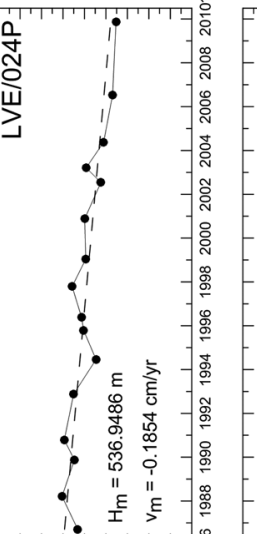

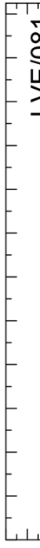

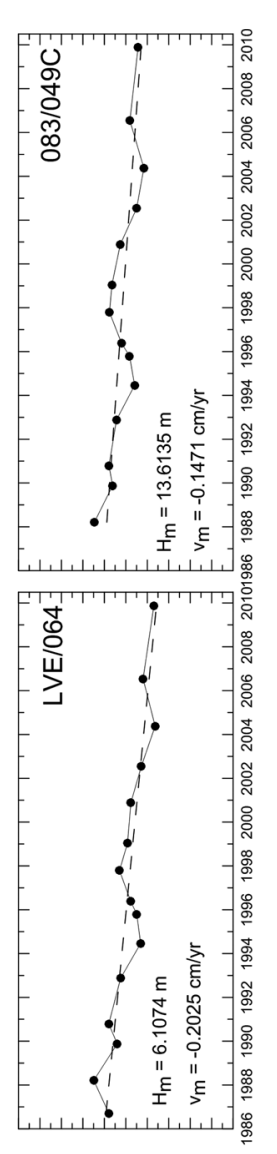

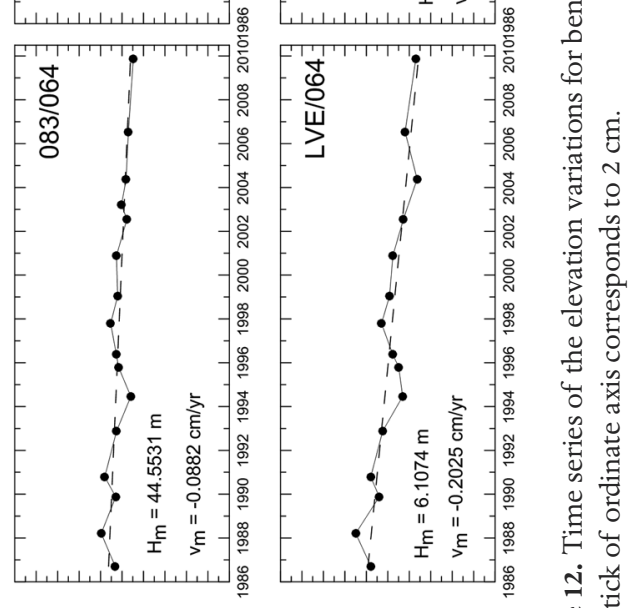




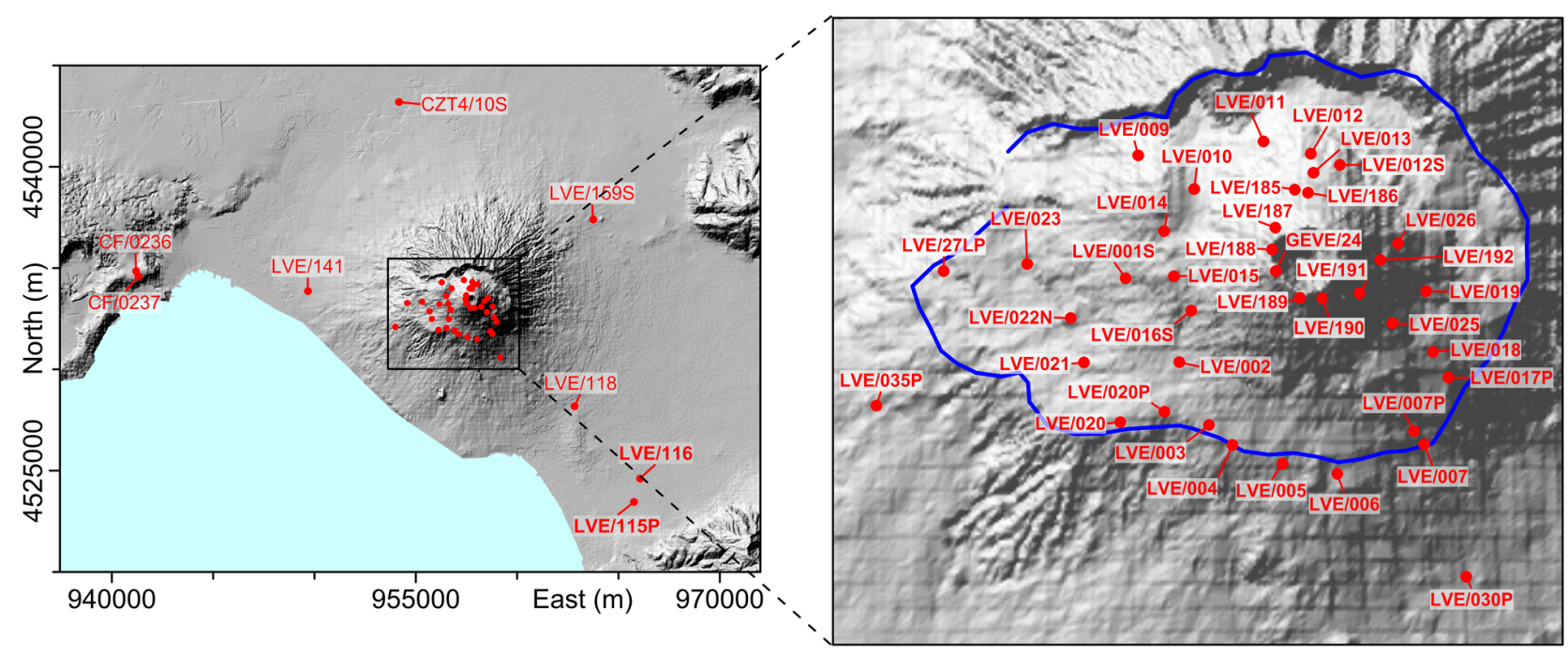

Figure 13. Map showing the position of the 47 benchmarks whose elevation variations time series were found to be non-stationary. Stationarity analysis is here based on the $t$-test. The blue line represents the rim of the Somma caldera.

order to easily compare them to each other and to verify the eventual existence of common behavior.

In Figures 14 and 15 we can observe that most of the altitude series exhibit a common behavior, indeed they look to be linearly correlated with a very similar shape. The only differences can be easily attributed to the length of the series. Indeed, in Figure 14 we show the series with $n>8$, whereas in Figure 15 the series with $\mathrm{n}=6$ exhibits a shape similar to the series in Figure 14. Only 8 time series (see Figure 13 for their geographical position) exhibit a more variable shape. They have been plotted in different panels of Figure 16 to better recognize their differences. We remark that all series, displayed in Figures 14 and 15, are recorded at the top of the volcano. On the contrary, among the stations whose measure series are characterized by a more vari-

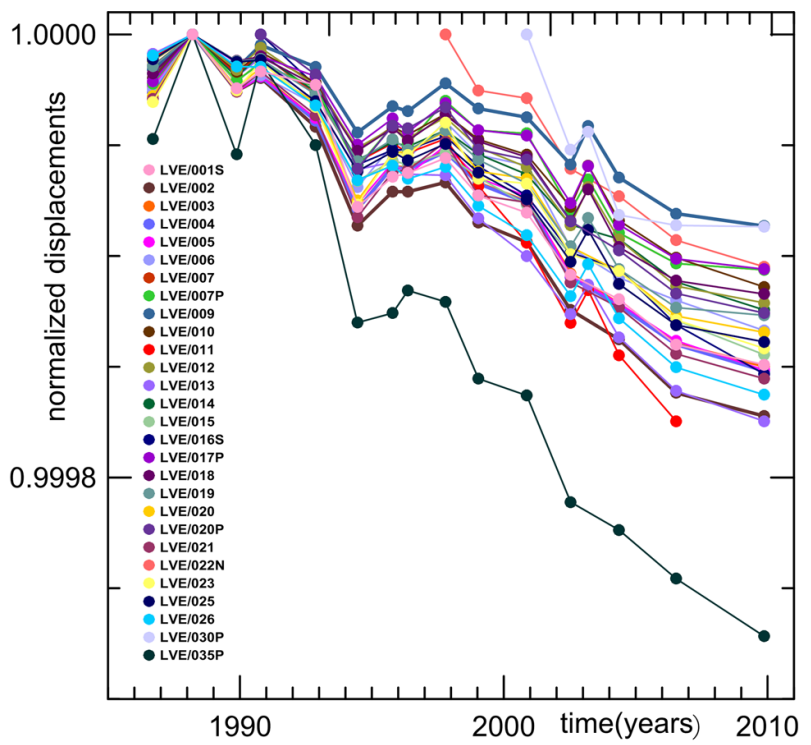

Figure 14. Time series of the elevation variations normalized to the maximum value of each series and having a number of samples larger than 8. able shape, 4 are located east of the volcano in the Sarno river plain (see Figure 13), the others are isolated points located west and north of the volcano.

However all of them appear to vary approximately linearly. We have verified this hypothesis applying the Ftest and performing a linear fit providing the vertical displacement velocities $\mathrm{v}$. These are reported in the map of Figure 17, where it is evident that the highest velocity of vertical ground displacement is observed at the crater area with a maximum value of more than $-1.5 \mathrm{~cm} / \mathrm{yr}$. Notice that, once again, there are isolated zones at higher velocity along the Sarno river plain and at west and north of the volcano. The first one can be explained by the aquifer dynamics, whereas the other could be due to very local dynamical processes. These results are also confirmed by the velocity distributions,

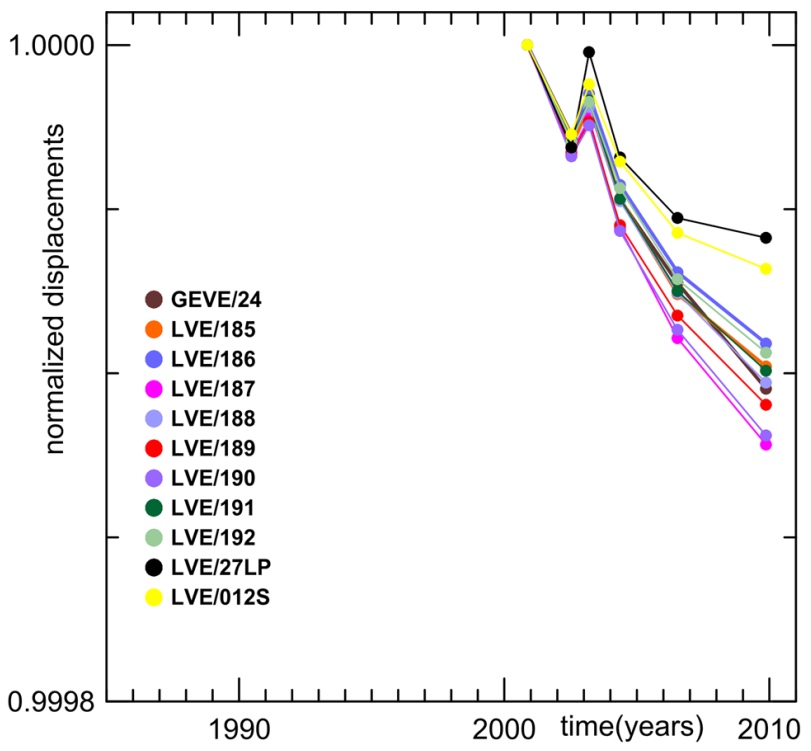

Figure 15. Time series of the elevation variations normalized to the maximum value of each series and having a number of samples equal to 6 . 

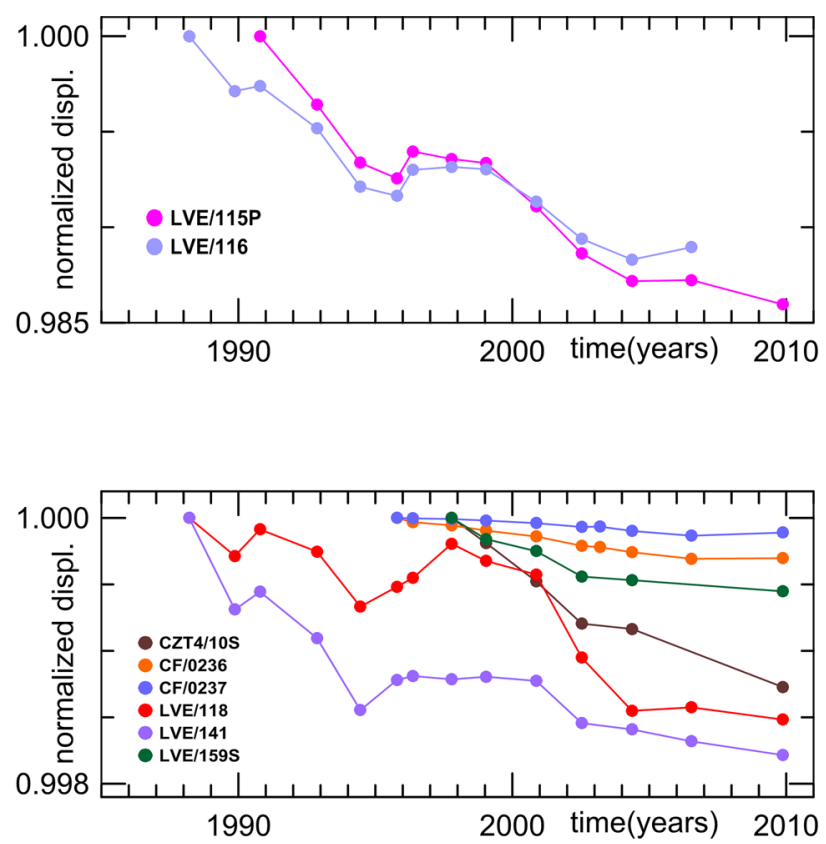

Figure 16. Time series of the elevation variations normalized to the maximum value of each series for 2 benchmarks (top) with a steeper slope and for other 6 benchmarks (bottom) showing variable slope.

calculated for the 47 non-stationary time-series, with respect to the benchmark elevation ( $h$ ) (Figure 18). After a transition zone for $600<h<800 \mathrm{~m}$ a.s.l., the subsidence rate exhibits a sharp increase for $h>800 \mathrm{~m}$ a.s.l. reaching the value $-1.6 \mathrm{~cm} / \mathrm{y}$ at $h=1174 \mathrm{~m}$ a.s.l. A significant subsidence $\left(\mathrm{v}_{\mathrm{m}}<-0.4 \mathrm{~cm} / \mathrm{y}\right)$ is also observed

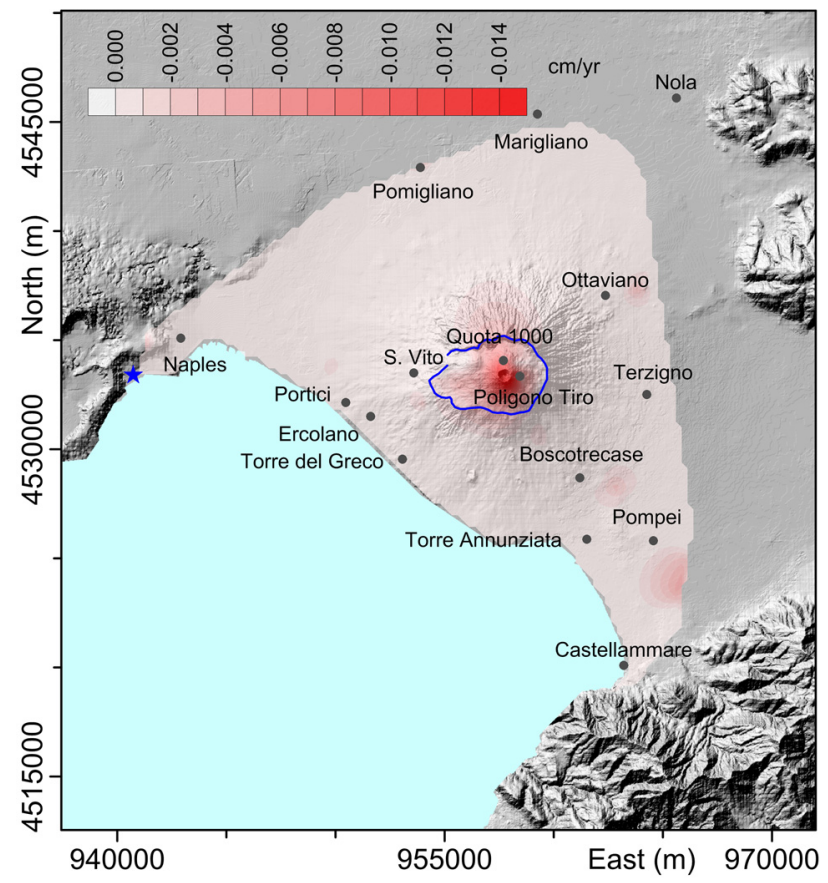

Figure 17. Map of the subsidence velocity calculated with the 47 benchmarks, whose vertical displacements time series were not stationary. The rim (solid blue line) of the Somma caldera is also showed. The blue star indicates the reference benchmarks location. Some peculiar place names are also shown. for benchmarks at lower values of $\mathrm{h}(0 \div 100 \mathrm{~m}$ a.s.l. $)$. These are located at the Sarno river plain, whose major subsidence has already been reported in the literature [Pingue et al. 2000]. Interestingly, the CF/ 0236 benchmark, which also shows an anomalous subsidence velocity, is located in an area of Naples city where the subsidence has already been observed by PS survey [Vilardo et al. 2009, Terranova et al. 2012].

\section{Discussion and conclusion}

We have described the evolution of the precision leveling network operating on Mt. Vesuvius area (VALN) from 1973 until now, enlightening the improvements in its detection capability, resolution and geometrical configuration. At present time it is composed by 359 benchmarks along $270 \mathrm{~km}$, with a geometrical configuration consisting of 21 leveling loops. This configuration guarantees the internal consistence of the collected data and allows a good estimate of the deformation field on the volcano.

The network is connected to similar adjacent networks dedicated to monitoring both volcanic and tectonic active areas. This allows to evaluate eventual differential relative displacements of the different areas and to enlighten eventual reciprocal influence.

The eventual presence of relevant systematic errors in the collected data has been investigated by using the variance analysis of discrepancies. This method can be applied also to data collected in periods during which the network was spatially limited to the medium-high part $(h<600 \mathrm{~m}$ a.s.l. $)$ of the volcano with no reliable reference benchmark. The analysis reveals that almost all the discrepancies of each measurement campaign are lower than the allowed tolerance. The discrepancy distributions are unimodal with a central value close to zero and very small standard deviations revealing the substantial absence of any significant systematic errors.

From 1986 up to now the definition of a stable reference point has allowed the rigorous data adjustment and the estimate of the benchmark elevation in the least squares sense. The adjustment processes evidence maximum residues lower than $1.5 \mathrm{~mm}$ with a standard deviation of the weighted units less than $1.8 \mathrm{~mm}$. Then we have been able to evaluate the height variation along some characteristic leveling profiles deducing the behavior of the deformation field. This enlighten a general subsidence of the whole volcano in the period 1986-2009, which assume larger values in the Mt. Vesuvius Gran Cono area. This behavior is more relevant along the crater rim where we observe a maximum subsidence of $-13.88 \mathrm{~cm}$ during the period 2000-2009.

We have reconstructed the elevation time series from 1986 to 2009 for 312 benchmarks of the network. 


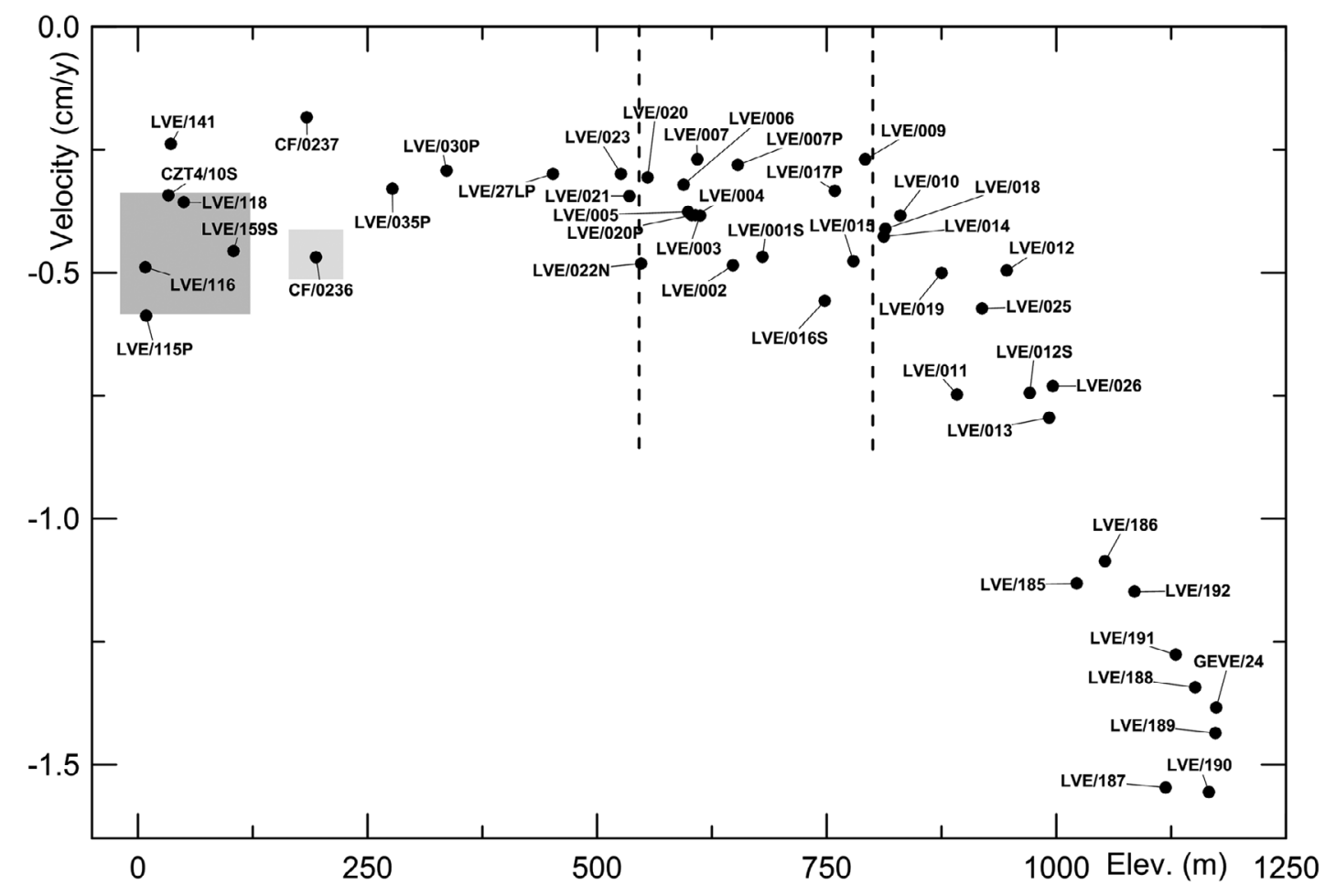

Figure 18. Subsidence velocities of the non-stationary benchmarks shown in Figure 13 versus the elevation of the benchmarks themselves. The points enclosed by squares refer to benchmarks exhibiting an anomalous velocity (see text for details).

Their stationarity has been established by a $t$-test and the time behavior of the displacements has been investigated for each non stationary benchmark. These exhibit a clear decrease with time confirming the existence of a subsidence phenomenon. The reconstruction of the subsidence velocity field in space evidences that subsidence velocities are larger for benchmarks located about at $h>800 \mathrm{~m}$ a.s.l. Other subsidence zones can be recognized in the Sarno plain, north of the volcano and in Naples city. These have been already observed using different measurement methods [Vilardo et. al. 2009, Terranova et al. 2012].

In conclusion we observe that the whole Vesuvius area is affected by a slight subsidence phenomenon which become more significant as the distance from the crater decreases. In particular the rim of the Somma caldera seems to sign the limit between two zones with different subsidence velocities.

This result can have many interpretations: 1) a deflating shallow magma chamber due to magma cooling or drainage [Murray and Wooler 2002, de Zeeuw-van Dalfsen et al. 2005], 2) hydrothermal processes implying a fluid loss from a shallow geothermal reservoir [Nakaboh et al. 2003, Gambino and Guglielmino 2008], 3) downslope creeping, settling and compaction of edifice, gravitational spreading [Borgia 1994, Murray and Wooler 2002].

The first hypothesis would imply a very shallow magma chamber. In fact a deeper deformation source should generate a larger deformation field at $500<h<$
$<800$ m a.s.l. than the observed one. Moreover, the horizontal ground displacement is not compatible with a deep deflating magma chamber [Tammaro et al. 2013]. On the contrary, seismic investigations revealed the presence of shallow magmatic bodies at larger depth [Zollo et al. 1996, Auger et al. 2001, De Natale et al. 2001, Del Pezzo et al. 2006]. On the basis of these considerations we can discharge the first hypothesis.

The second hypothesis is not supported by geochemical observations. In fact gas flux and temperature show a slight decrease in the last 15 years [Granieri et al. 2010, Caliro et al. 2011], therefore there are no evidences of strong change of the hydrothermal system under the volcano.

Therefore we conclude that the third hypothesis is the most likely. We think that a simple interpretation of the data could be provided by observing that the Gran Cono area is the youngest part of the whole Somma-Vesuvius volcanic complex and therefore the deposits of this area are less coherent and consolidated with respect to the oldest Somma deposits. This leads to conclude that the subsidence phenomenon can be mainly due to the sliding and the compaction of these incoherent materials, although we do not exclude that a minor contribution may be due to other sources.

Acknowledgements. The work benefits from highly positive and obscure contribution of all the surveys operators that have followed over the years. We thank greatly two anonymous reviewers and the Associate Editor M. La Rocca for their constructive comments and suggestions. 


\section{References}

Auger, E., P. Gasparini, J. Virieux and A. Zollo (2001). Seismic evidence of an extended magmatic sill under Mt. Vesuvius, Science, 294, 1510-1512.

Battaglia, M., C. Troise, F. Obrizzo, F. Pingue and G. De Natale (2006). Evidence for fluid migration as source of deformation at Campi Flegrei caldera (Italy), Geophys. Res. Lett., 33, L01307; doi: 10.1029/ 2005 GL024904.

Beauducel, F., G. De Natale, F. Obrizzo and F. Pingue (2004). 3D modelling of Campi Flegrei ground deformations: An example of trade-off between source and structure, Pure Appl. Geophys., 161 (7), 13291344; doi 10.1007/s00024-004-2507-4.

Berrino, G., U. Coppa, G. De Natale and F. Pingue (1993). Recent geophysical investigation at SommaVesuvio volcanic complex, J. Volcanol. Geoth. Res., 58, 239-262.

Bianco, F., M. Castellano, G. Milano, G. Ventura and G. Vilardo (1998). The Somma-Vesuvius stress field induced by regional tectonics: Evidences from seismological and mesostructural data, J. Volcanol. Geoth. Res., Special Issue Vesuvius edited by F.J. Spera, B. De Vivo, R.A. Ayuso and H.E. Belkin, 82 (1-4), 199-218.

Bianco, F., M. Castellano, G. Milano, G. Vilardo, F. Ferrucci and S. Gresta (1999). The seismic crises at Mt. Vesuvius during 1995 and 1996, Phys. Chem. Earth (A), 24 (11-12), 977-983.

Bonasia, V., M. Ferri, S. Montagna and F. Pingue (1974). Le deformazioni del suolo quale mezzo d'indagine sulla dinamica vulcanica al Vesuvio ed a Vulcano, Rivista Italiana di Geofisica, 23 (3-4), 141-144.

Bonasia, V., and F. Pingue (1981). Ground deformations on Mt. Vesuvius from 1977 to 1981, Bulletin Volcanologique, 44 (3), 513-519.

Bonasia, V., E. Del Pezzo, F. Pingue, R. Scandone and R. Scarpa (1985). Eruptive history, seismic activity and ground deformations at Mt. Vesuvius, Italy, Annales Geophysicae, 3 (3), 395-406.

Borgia, A. (1994). Dynamic basis of volcanic spreading, J. Geophys. Res., 99 (B9), 17791-17804.

Bottiglieri, M., M. Falanga, U. Tammaro, F. Obrizzo, P. De Martino, C. Godano and F. Pingue (2007). Independent component analysis as a tool for ground deformation analysis, Geophy. J. Int., 168 (3), 1305-1310; doi:10.1111/j.1365-246X.2006.03264.x. ISSN:0956$540 \mathrm{X}$.

Bottiglieri, M., M. Falanga, U. Tammaro, P. De Martino, F. Obrizzo, C. Godano and F. Pingue. (2010). Characterization of GPS time series at Neapolitan volcanic area by statistical analysis, J. Geophys. Res., 115, B10416; doi:10.1029/2009JB006594.
Brocchini, D., C. Principe, D. Castradori, M.A. Laurenzi and L. Gorla (2001). Quaternary evolution of Southern sector of the Campanian Plain and early SommaVesuvius activity: insights from the Trecase 1 well, Miner. Petr., 73 (1-3), 67-91.

Caliro, S., G. Chiodini, R. Avino, C. Minopoli and B. Bocchino (2011). Long time-series of chemical and isotopic compositions of Vesuvius fumaroles: evidence for deep and shallow processes, Annals of Geophysics, 54 (2), 137-149; doi:10.4401/ag-5034.

Carta, S., R. Figari, G. Sartoris, E. Sassi and R. Scandone (1981). A statistical model for Vesuvius and its volcanological implications, Bull. Volcanol., 44, 129-151.

Cascini, L., S. Ferlisi, G. Fornaro, R. Lanari, D. Peduto and G. Zeni (2006). Subsidence monitoring in Sarno urban area via multi-temporal DInSAR tecnique, Int. J. Remote Sensing, 27 (8), 1709-1716.

Chiodini, G., L. Marini and M. Russo (2001). Geochemical evidences of high temperature hydrothermal brines at Vesuvio volcano (Italy), Geochimica et Cosmochimica Acta, 65 (13), 2129-2147.

Commissione Geodetica Italiana (1975). Guida alla progettazione ed all'esecuzione delle livellazioni geometriche, Boll. Geod. Soc. Aft., 34 (1), 1-15.

Corrado, G., I. Guerra, A. Lo Bascio, G. Luongo and R. Rampoldi (1976). Inflation and microearthquake activity of Phlegraen Fields, Italy, Bull. Volcanol., 40 (3), 169-188.

Cubellis, E., G. Luongo and A. Marturano (2007). Seismic hazard assessment at Mt. Vesuvius: the maximum magnitude expected, J. Volcanol. Geoth. Res., 162, 139-149; doi:10.1016/j.jvolgeores.2007.03.003.

Delibrias, G., G.M. Di Paola, M. Rosi and R. Santacroce (1979). La storia eruttiva del complesso vulcanico del Somma Vesuvio ricostruita dalle successioni piroclastiche del Monte Somma, Rendiconti della Società Italiana di Mineralogia e Petrologia, 35 (1), 411-438.

Del Pezzo, E., F. Bianco, L. De Siena and A. Zollo (2006). Small scale shallow attenuation structure at Mt. Vesuvius, Italy, Phys. Earth Planet. Inter., 157, 257-268.

De Natale, G., P. Capuano, C. Troise and A. Zollo (1998). Seismicity at Somma-Vesuvius and its implications for the 3D tomography of the volcano, J. Volcanol. Geoth. Res., Special Issue Vesuvius edited by F.J. Spera, B. De Vivo, R.A. Ayuso and H.E. Belkin, 82 (1-4), 175-197.

De Natale, G., C. Troise, F. Pingue, P. De Gori and C. Chiarabba (2001). Structure and dynamics of the Somma-Vesuvius volcanic complex, Mineralogy and Petrology, 73, 5-22.

De Natale, G., C. Troise, R. Trigila, D. Dolfi and C. Chiarabba (2004). Seismicity and 3-D substructure 
at Somma-Vesuvius volcano: evidence for magma quenching, Earth Planet. Sci. Lett., 221, 181-196.

de Zeeuw-van Dalfsen, E., H. Rymer, F. Sigmundsson and E. Sturkell (2005). Net gravity decrease at Askja volcano, Iceland: Constraints on processes responsible for continuous caldera deflation, 1988-2003. J. Volcanol. Geoth. Res., 139 (3-4), 227-239.

Dzurisin, D. (2000). Volcano geodesy: challenges and opportunities for the 21st century, Phil. Trans. R. Soc. Lond., 358, 1547-1566; doi 10.1098/rsta.2000. 0603 .

Dvorak, J., and D. Dzurisin (1997). Volcano Geodesy: the search for magma reservoirs and the formation of eruptive vents, Reviews of Geophysics, 35 (3), 343-384.

Dzurisin, D. (2003). A comprehensive approach to monitoring volcano deformation as a Window on the eruption cycle, Reviews of Geophysics, 41 (1), 1001; doi:10.1029/2001RG000107.

Fabbrocino, S., R. Lanari, P. Celico, G. Termolini and G. Zeni (2007). Groundwater Pumping and Land Subsidence in the Sarno River Plain (Campania), Memorie Descrittive della Carta Geologica d'Italia, 76, 163-174.

Finetti, I., and A. Del Ben (1986). Geophysical study of the Tyrrhenian opening, Bollettino di Geofisica Teorica e Applicata, 27, 74-115.

Frondini, F., G. Chiodini, S. Caliro, C. Cardellini, D. Granieri and G. Ventura (2004). Diffuse $\mathrm{CO}_{2}$ soil degassing at Vesuvio, Italy, Bull. Volcanol., 66, 642-651; doi:10.1007/s00445-004-0346-x.

Gambino, S., and F. Guglielmino (2008). Ground deformation induced by geothermal processes: a model for La Fossa Crater (Vulcano Island, Italy), J. Geophys. Res., 113, B07402; doi:10.1029/2007JB005016.

Giannoni, U. (1962). Livellazione geometrica lungo il mantello del Vesuvio, Annali dell'Osservatorio Vesuviano, 6th series, 4, 27-92.

Granieri, D., R. Avino and G. Chiodini (2010). Carbon dioxide diffuse emission from the soil: ten years of observations at Vesuvio and Campi Flegrei (Pozzuoli), and linkages with volcanic activity, Bull. Volcanol., 72, 103-118; doi:10.1007/s00445-009-0304-8.

Landi, P., A. Bertagnini and M. Rosi (1999). Chemical zoning and crystallization mechanisms in the magma chambre of the Pomici di Base plinian eruption of the Somma-Vesuvius (Italy), Contrib. Mineral. Petrol., 135, 179-197.

Loperfido, A. (1914). Livellazione dell'isola di Ischia e Vesuvio eseguita nel 1913, Pubbl. della Reale C.G.I.M., Firenze.

Luongo, G., E. Cubellis, F. Obrizzo and S.M. Petrazzuoli (1991). A physical model for the origin of volcanism of the Tyrrhenian margin: the case of the neapolitan area, J. Volcanol. Geoth. Res., 48, 173-185.

Luongo, G., A. Perrotta, C. Scarpati, E. De Carolis, G. Patricelli and A. Ciarallo (2003). Impact of the A.D. 79 explosive eruption on Pompeii, II. Causes of death of the inhabitants inferred by stratigraphic analysis and areal distribution of the human casualties, J. Volcanol. Geoth. Res., 126, 169-200.

Marturano, A. (2008). Sources of ground movement at Vesuvius before the A.D. 79 eruption: Evidence from contemporary accounts and archaeological studies, J. Volcanol. Geoth. Res., 177, 959-970; doi: 10.1016/j.jvolgeores.2008.07.017

Marturano, A., G. Aiello and D. Barra (2011). Evidence for Late Pleistocene uplift at the Somma-Vesuvius apron near Pompei, J. Volcanol. Geoth. Res., 202, 211-227.

Mastrolorenzo, G., D. Palladino, G. Vecchio, J. Taddeucci (2002). The 472 A.D. Pollena eruption of Somma-Vesuvius (Italy) and its environmental impact at the end of the Roman Empire, J. Volcanol. Geoth. Res., 113, 19-36.

Meo, M., U. Tammaro and P. Capuano (2008). Influence of topography on ground deformation at Mt. Vesuvius (Italy) by finite element, Int. J. Non-Lin. Mech., 43, 178-186.

Mogi, K. (1958). Relations between the eruptions of various volcanoes and the deformation of the ground surface around them, Bull. Earth. Res. Inst. Univ. Tokyo, 36, 99-134.

Murray, J.B., and L.K. Wooller (2002). Persistent summit subsidence at Volcán de Colima, Mexico,19821999: strong evidence against Mogi deflation, J. Volcanol. Geoth. Res., 117 (1-2), 69-78.

Nakaboh, M., H. Ono, M. Sako, Y. Sudo, T. Hashimoto and A.W. Hurst (2003). Continuing deflation by fumaroles at Kuju Volcano, Japan. Geophys. Res. Lett., 30 (7), 1396; doi:10.1029/2002GL016047.

Obrizzo, F, F. Pingue, C. Troise and G. De Natale (2001). Coseismic displacements and creeping along Pernicana Fault (Mt. Etna) in the last seventeen years: a detailed study of a structure on a volcano, J. Volcanol. Geoth. Res, 109, 109-131.

Obrizzo, F., F. Pingue, C. Troise and G. De Natale (2004). Bayesian inversion of 1994-1998 vertical displacements at Mt. Etna: evidence for magma intrusion, Geophys. J. Int., 157, 935-946.

Palmieri, L. (Relatore), E. Capocci, G. Giordano, F. Schiavoni, R. Cappa and G. Giuscardi (1862). Intorno all'incendio del Vesuvio cominciato il dì 8 dicembre 1861, Rendiconto delle Tornate dell'Accademia Pontaniana, Napoli, anno X, tornata 9 marzo, 40-61, tornata 23 marzo, 72-83. 
Patacca, E., and P. Scandone (2007). Geology of the Southern Apennines, Bollettino della società Geologica Italiana, supplement 7, 75-119.

Pelton, J.R., and R.B. Smith (1982). Contemporary vertical surface displacements in Yellowstone National Park, J. Geophys. Res., 87 (B4), 2745-2761.

Pingue, F., and T. Esposito (1988). Misure di livellazione di precisione nell'area vesuviana, Bollettino di Geodinamica e Scienze Affini, 47 (3), 275-300.

Pingue, F., and T. Esposito (1994). Levelling measurements on Vesuvius in the period 1986-1992, In: L. Villari (ed.), Data related to Eruptive Activity, Unrest Phenomena and Other Observations on the Italian Active Volcanoes 1992, Acta Vulcanologica, 6, 70-75.

Pingue, F., G. Berrino, P. Capuano, F. Obrizzo, G. De Natale, T. Esposito, C. Serio, U. Tammaro, G. De Luca, R. Scarpa, C. Troise and G. Corrado (2000). Ground Deformation and gravimetric monitoring at SommaVesuvius and Campanian volcanic area (Italy), Phys. and Chem. of the Earth, 25 (9-11), 747-754.

Rolandi, G., F. Bellucci and M. Cortini (2004). A new model for formation of the Somma Caldera, Mineralogy and Petrology, 80 (1-2), 27-44; doi:10.1007/ s00710-003-0018-0.

Santacroce, R. (1983). A general model for the behaviour of the Somma-Vesuvius volcanic complex, J. Volcanol. Geoth. Res., 17 (1-4), 237-248.

Santacroce, R., and A. Sbrana, eds. (2003). Geological Map of Vesuvius 1:15,000 scale, S.EL.CA., Firenze.

Tammaro, U., P. De Martino, F. Obrizzo, G. Brandi, A. D’Alessandro, M. Dolce, S. Malaspina, C. Serio and F. Pingue (2013). Somma Vesuvius volcano: ground deformations from CGPS observations (2001-2012), Annals of Geophysics, 56 (4), S0456; doi:10.4401/ag6462.

Terranova, C., G. Vilardo, R. Isaia, E. Iannuzzi and F. Pignataro (2012). Telerilevamento e classificazione delle subsidenze nell'area metropolitana di Napoli tramite interpretazione di dati interferometrici radar ps, Geologia Tecnica e Ambientale, 1/12, 10-37.

Ventura, G., and G. Vilardo (1999). Slip tendency analysis of the Vesuvius faults: implications for the seismotectonic and volcanic hazard assessment, Geophys. Res. Lett., 26 (21), 3229-3232.

Vezzani, L., A. Festa and F. Ghisetti (2010). Geology and Tectonic Evolution of the Central-Southern Apennines, Italy, Geological Society of America, Special Paper 469, 1-58.

Vilardo, G., G. Ventura, C. Terranova, F. Matano and S. Nardò (2009). Ground deformation due to tectonic, hydrothermal, gravity, hydrogeological, and anthropic processes in the Campania Region (Southern
Italy) from Permanent Scatterers Synthetic Aperture Radar Interferometry, Remote Sensing of Environment, 113, 197-212; doi:10.1016/j.rse.2008.09.007.

Zollo, A., P. Gasparini, J. Virieux, H. Le Meur, G. De Natale, G. Biella, E. Boschi, P. Capuano, R. De Franco, P. Dell'Aversana, R. De Matteis, I. Guerra, G. Iannaccone, L. Mirabile and G. Vilardo (1996). Seismic evidence for a low-velocity zone in the upper crust beneath Mount Vesuvius, Science, 274, 592-594.

\footnotetext{
${ }^{\star}$ Corresponding author: Folco Pingue, Istituto Nazionale di Geofisica e Vulcanologia, Sezione di Napoli, Osservatorio Vesuviano, Naples, Italy; email: folco.pingue@ov.ingv.it.

(C) 2013 by the Istituto Nazionale di Geofisica e Vulcanologia. All rights reserved.
} 